\title{
BELIEVE IT OR NOT: YOUTH AND YOUNG ADULT FEMALE PERCEPTIONS OF THE CREDIBILITY OF ONLINE MULTIMEDIA MESSAGES
}

A thesis presented to the Faculty of the Graduate School

University of Missouri-Columbia

In Partial Fulfillment

of the Requirements for the Degree

Master of Arts

\section{by \\ ANA ADI}

Dr. Paul Bolls, Thesis Supervisor 
The undersigned, appointed by the dean of the Graduate School, have examined the thesis entitled

BELIEVE IT OR NOT: YOUTH AND YOUNG ADULT FEMALE PERCEPTIONS OF THE CREDIBILITY OF ONLINE MULTIMEDIA MESSAGES

Presented by Ana Adi,

A candidate for the degree of Master of Arts,

And hereby certify that, in their opinion, it is worthy of acceptance.

Professor Paul Bolls

Professor Glen Cameron

Professor Kevin Wise

Professor Louise Miller 


\section{¿ ACKNOLEDGEMENTS \&}

I would like to express my appreciation for Dr. Paul Bolls, my thesis supervisor and academic advisor, for supporting me and encouraging me thorough this amazing journey of academic discovery. He sensed my boundaries

and pushed me to surpass them, by taking challenges that I never thought I could ever meet. He taught me in this way two valuable lessons, one of life and one of research: to believe in myself and to always aim for more than the best. I thank him for that and I am grateful for having been challenged to explore the quantitative research.

I am also very grateful to the members of my thesis committee: Dr. Glen T. Cameron, Dr. Kevin Wise and Dr. Louise Miller for their input, constant support, for their time and valuable explanations. I am grateful for the enthusiasm they inspired me with and for tolerating my inquisitive questions, as I am most appreciative for the time they took to guide me through this incredible journey.

Finally, I am obliged to my friends and colleagues: David Schneider for having filmed the messages of the experiment and Michael M. Martinez for having played the spokesperson for this research. 


\section{\& TABLE OF CONTENTS \&}

ACKNOWLEDGEMENTS........................................................... ii

LIST OF FIGURES AND TABLES …........................................

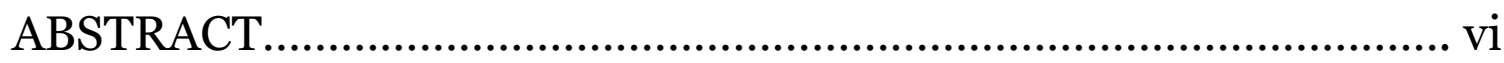

\section{Chapter}

INTRODUCTION.......................................................... 1

CHAPTER 1...............................................................p.4

1.1. Health communication, the HPV virus and the HPV vaccine

1.2. Theoretical context - LC4MP model

1.3. Defining concepts

1.3.1. What is a source?

1.3.2 What is credibility?

1.3.3. What makes a source credible? - defining source credibility

1.3.4. Taking source credibility online

1.4. Health information online

1.4.1. Online sources and the health information

1.4.2. Youth and young adult health information seekers

1.4.3. Risk and benefits - communicating immunization information online

CHAPTER 2

2.1. Methodology

2.2. Research design

2.3. Independent variables

2.4. Dependent variables

2.5. Participants and procedure

CHAPTER 3

3.1. Manipulation check

3.2. McCroskey Scale reliability check

3.3. Research question 1

3.4. Research question 2

3.5. Research question 3 
CHAPTER 4 ……............................................................... 39

4.1. Discussion

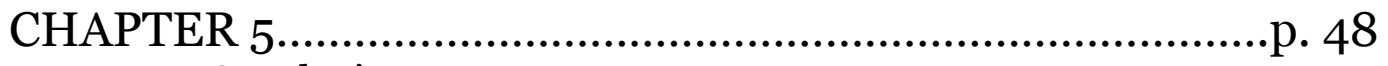
5.1. Conclusions

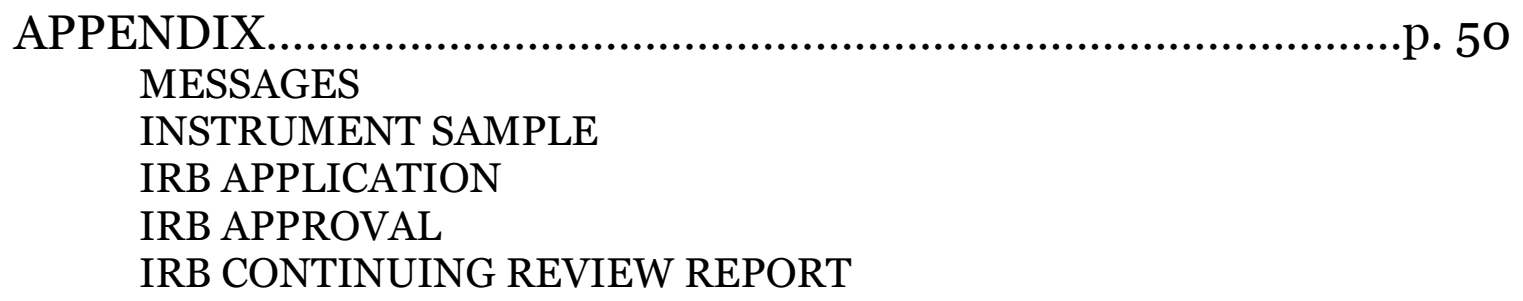

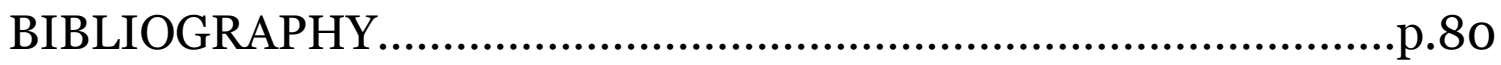

\section{ATTACHMENTS}

The three multimedia messages used for the experiment:

Positive.mp4

Coactive.mp4

Negative.mp4 


\section{¿ LIST OF FIGURES AND TABLES \}

Figure 1. Lasswell's communication process...................................... p. 12

Table 1. Emotional tone pairwise comparisons for manipulation check.

Table 2. Chronbach's Alpha for perceived credibility dimensions............p.35

Table 3. Means for perceived source credibility according to the emotional tone of the message...........................................................p. 36

Table 4. Pairwise comparisons between the positive, negative and coactive emotional tones..................................................................p. 36

Table 5. Paired sampled correlations of respondents' willingness to forward a message having a different emotional tone...........................p. 37 
BELIEVE IT OR NOT: YOUTH AND YOUNG ADULT FEMALE PERCEPTIONS OF THE CREDIBILITY OF ONLINE MULTIMEDIA MESSAGES

Ana ADI

Dr. Paul Bolls, Thesis Supervisor

\begin{abstract}
In the age of Internet, multimedia messages and speed information, it is highly important for communicators to design and create more effective messages to reach their targets. This research addressed the issue of message design by investigating the impact the emotional tone of an online multimedia message has on the perception of the source releasing it. It also explored the influence of the emotional tone on the number of people to whom respondents would forward the messages to and the impact on their comprehension and recognition of risk and benefit information. A 2 (source) x 3 (emotional tone) factorial design online experiment was conducted on youth and young adult women. Results showed that the emotional tone of a message influences the way the respondents perceive the credibility of the source releasing it as well as it influences the number of people to whom respondents would forward the message. Also, risk statements were proven to be better recognized than the benefit ones. Furthermore, implications of the findings on future message design as well as future research directions are discussed.
\end{abstract}




\section{¿ INTRODUCTION \&}

The dynamics of health information and communication have changed substantially with the birth of the Internet. The popularity of the Internet as the source of information on health related issues is due to the ease in access and use, and the straightforward descriptions available on the websites. According to recent data, $4.5 \%$ of all Internet searches are health related (Morahan-Martin, 2004) while more than 93\% of online health seekers justify their choice by saying that the Internet allows them to get the information they are interested in at a time that is convenient to them (Fox, 2001). Moreover, $70 \%$ of the health seekers say that the information they found online had influenced their decisions about how to treat an illness or condition, a percentage much higher than that of those who actually decided to follow-up with a specialist and confirm or infirm the information they found online.

"The typical health seeker starts at a search site, not a medical site, and visits two to five sites during an average visit” (Fox et. al., 2001) without usually going further in their search than the first page of search engine results (Morahan-Martin, 2004). An average of thirty minutes of online search is enough for the user to get information on the problem of interest and to decide whether to trust it or not. Generally, if the website seems to be selling something, the user closes the window and navigates away from it. The 
opposite happens though when health seekers believe that the information found is consistent with what they already know: $87 \%$ of those asked claim that they have more confidence in those sites (Fox \& Lee, 2002).

The same information search pattern is noticed in the youth and young adult population group among whom online health related searches are increasingly popular (Hanauer, Dibble, Fortin, \& Col, 2004). The main reasons for this behavior are the ease in using the Internet and the anonymity it provides (Kanuga \& Rosenfeld, 2004). Accessibility is also a crucial factor, most youths and young adults, at least in the USA and the UK, being able to and accessing it from school, home and elsewhere (Gray, Kleinb, Noycec, Sesselberg, \& Cantrill, 2005). Additionally, although general research shows that most health seekers go online because they or someone close to them has been or is likely to be diagnosed with a specific disease (Fox et. al., 2001), youths and young adults are more proactive in their searches as they are looking for information that they are either too embarrassed, afraid or uncomfortable to discuss with their parents, peers and health practitioners (Goold, Ward, \& Carlin, 2003; Gray, Kleinb, Noycec, Sesselberg, \& Cantrill, 2005; Hansen, Derry, Resnic, \& Richardson, 2003; Kanuga \& Rosenfeld, 2004; Neumark-Sztainer, 2001; Thornburg, 1981; van den Berg \& Parry, 1983). Sexuality, body changes and sexually transmitted diseases (STDs) are only some of those topics that youths and young adults would rather search by themselves than discuss them with someone else (Ackard \& Neumark- 
Sztainer, 2001). This also accounts for the popularity and presence of several teen health websites (www.iwannaknow.com; www.teenagehealthfreak.com; www.teenhealthfx.com) about whose credibility and trustworthiness questions have been raised. Additionally, new questions regarding how youths and young adults perceive and process information emerged, special attention being dedicated to the form - be it text, audio, video - (Fahmy \& Wanta, 2005) and emotional tone of the message (Bolls, 2001).

The present research is focusing on similar questions in an attempt to bring fresh knowledge and evidence that would facilitate the production of more efficient messages targeting youths and young adults and that would also help maintain if not improve the credibility index of the sources releasing them. Therefore, this study will focus on how the emotional tone of online multimedia health information affects the credibility of a source and the respondents' behavior of forwarding the information the have just received to their peers. Moreover, this research will identify whether the negative or positive information presented in online multimedia messages affect comprehension. 


\section{\& CHAPTER 1 d}

This chapter 1 reviews the literature related to online source credibility and message comprehension. Concepts of source, credibility, and source credibility will be explained. Moreover, it outlines the limited capacity model of mediated message processing (LC4MP) that serves as the framework of analysis for this study.

\subsection{Health communication, the HPV virus and the HPV vaccine}

The infection with the Human Papillomavirus (HPV) is a common sexually transmitted disease nowadays, affecting 6.2 million people in a year in the United States only (Markowitz, Dunne, Saraiya, Lawson, Chesson, \& Unger, 2007). It is a viral disease caused by the HPV virus, whose high-risk strains may cause cervical cancer and lead to male and female infertility while the low-risk strains cause genital warts. The virus spreads during sexual intercourse, whether it is vaginal, anal, or oral and can be passed from one individual to another through genital skin-to-skin contact, from the mouth, from the rectum and/or in the semen. An infected mother may also infect her child with HPV during vaginal birth (Hoover, Carfioli \& Moench, 2000; Homer, 2004). However, HPV viral infection is difficult to prevent because 
infection is through direct contact so that spread of the virus is not fully preventable by the use of latex condoms. HPV viral infection has minimal symptoms, allowing transmission from partners who are unaware they are infected. The lack of symptoms makes diagnosis difficult for health providers. Furthermore, "HPV affects people differently. Most cases of HPV are transient because the immune system can fight off the virus and the infected person is left unharmed. However, people with weakened immune systems or those infected with more virulent strains of HPV may become symptomatic" (Homer, 2004, p.8). In addition to the medical risks, there is social stigma related to HPV as a category of Sexually Transmitted Diseases, stigma which made the communicators' task to increase awareness about it even more difficult (Hoover, Carfioli \& Moench, 2000).

Additionally, previous research shows that there is little awareness, knowledge, and understanding of the HPV virus, risks of HPV infection, symptoms and prevention among youth and young adult populations as well as among women with abnormal Pap smear tests (Biro, Rosenthal, Kollar, \& Hillard, 1997; Horn, McQuillan, Ray, \& Hook, 1990; Jennings, 1997; Jubelirer et al., 1996; Ramirez, Ramos, Clayton, Kanowitz, \& Moscicki, 1997).

Last but not least, the beginning of 2007 marked a break-through for the medical world and for the general public as Merck launched Gardasil, the first HPV vaccine which although cannot cure previous HPV infections, can prevent the infection with four of the most common strains of the virus which are 
responsible for causing $70 \%$ of cervical cancer cases and $90 \%$ of genital warts ones (Merck, 2007). It is a long waited for break-through, the necessity of developing an HPV vaccine being noticed as early as 2000. Back then research investigated the attitudes of parents and youth and young adult females' towards the HPV virus itself and a potential vaccine against it (Hoover, Carfioli, \& Moench, 2000; Zimet et al., 2000). With the launching of the HPV vaccine, pharmaceutical companies, the Centers for Disease Prevention and Control, medical practitioners and even medical websites have to face a new challenge: making sure their messages about the HPV vaccine and virus are effective, meaning that they will not only increase the awareness about the existence of the immunization opportunity but also determine a change in people's behavior and have them take action and get vaccinated. Having this challenge in mind, this research is going to explore which emotional tone message, be it positive, negative or coactive, is best recognized by respondents and which emotional tone is most likely to compel respondents to forward the information they have just received to their peers.

\subsection{Theoretical context}

- LC4MP model -

As the introduction and the previous subchapter showed, the topic of this thesis is strongly related to health communication, exploring concepts such as perceived credibility, recognition of mediated messages and behavior. While 
there is no single theory describing credibility and behavior, the LC4MP model has direct application to the recognition of mediated messages and the way they are processed. Furthermore, the LC4MP model has been recently revised and perfected by its author complying even more with the area of health communication. The LC4MP updates the working model of the limited capacity of mediated processing (LCMP) (Lang, 2000) that varies notions and concepts of the present model which is based on the cognitive psychology information-processing tradition (Berger, 1989) and on the research on the social effects of the mass communication (Lachman, 1979). This earlier version is a data-driven model based on two major assumptions: first, that people are information processors, and second, that people have limited abilities to process information. Moreover, the model suggests that there are three major information-processing subprocesses, namely encoding, storage and retrieval, which "can be performed in a cursory or a thorough manner" (Lang, 2000, p. 50). These subprocesses cannot be exercised perfectly and simultaneously due to the fact that the limited processing resources that an individual has are independently but not necessarily evenly allocated.

According to Lang (2000), the process of encoding is the one where the message is taken out from the environment and converted into a mental representation in the brain. For this to happen, a message has to engage one or more sensory preceptors, such as the eyes, ears, skin, nose or mouth. The message once perceived goes to a sensory store for a very short time. Although 
research suggests that there are separate stores for each sense and that their capacity may be unlimited, other studies demonstrated that information "resides in these stores for periods ranging from about 30omsec for the visual (called iconic) store to four or five seconds for the auditory (called echoic) store" (Lang, 2000, p. 48). The information stored in the sensory store represents actually bits from the original message that were chosen both intentionally and unintentionally, and which depends on a mixture of the subject's goals, knowledge, cultural background and environment as well as the stimulus' impact, novelty, and intensity. Therefore, when viewing a video or a multimedia message, the encoding sub-process works in two phases through which "specific bits of information contained in the original message are selected from the myriad of information bits available in the sensory store and transformed into activated mental representations working or short-term memory" (Lang, 2000, p. 48). Other pieces of information from the original message that do not meet the above criteria are simply overwritten. Nonetheless, when speaking about encoding of mediated messages, it is highly important to remember that in order for a message to catch someone's attention, it must engage the sensory receptors and have the subject convert intentionally and unintentionally bits of information from that message into mental representations to be stored in his/her working memory.

What happens next is that the newly encoded information is linked with previously encoded one. The more associations are formed between the new 
information received and the existing memories are formed, the better and the more completely the new information is stored. This is the essence of storage: the formation of a continuum from poorly to thoroughly stored bits of information, not all newly encoded information receiving an equivalent amount of processing.

Finally, retrieval happens when a person is either reactivating a stored mental representation or searching his/her associative memory network for a specific piece of information and reactivates it by bringing it back from the long-term memory into the working one. Furthermore, retrieval is an ongoing process as even during message reception or when receiving new information one needs previous information to understand it.

Therefore, the point that the LCMP model makes is that these three subprocesses, although happen simultaneously, do not receive the same resources, and it is the uneven allocation of resources that explains the differences in processing new information. In addition, the 2006 model, LC4MP, includes an updated list of assumptions, which allows for it to be applied for a better message design. Moreover, the new assumptions facilitate the understanding of how message structure and content interact with an individual's information-processing, and how much of a communication message is remembered. It also helps determine motivational activation which will affect the message perception. They are as follows: first, people have two underlying motivational systems. The aversive system is activated more 
quickly in threatening situations as it plays an auto-protection role, while the appetitive one is mainly activated in situations of information intake. Second, media are made up of a "variably redundant streams of information presented through multiple sensory channels (eyes, ears, touch) and formats (words, text, still pictures, moving pictures etc.)" (Lang, 2006). Third, human behavior is dynamic and so is human cognition. And fourth, communication is interactive and continuous in nature, as well as it is an embodied process.

According to the LC4MP model during mediated message use, controlled and automatic mechanisms continuously allocate processing resources to encoding, storage, and retrieval as a function of the structure, content, and motivational and personal relevance of the mediated message (Lang, 2006). In other words, individuals would react in a different way for example, to inverted pyramid style or essay style messages. Also, the theory implies that people would react differently to messages with different emotional tones, understanding by this that the messages are focusing on topics "about which people usually feel emotional” (Bolls, Lang, \& Potter, 2001, p. 627). Moreover, the fact that negative messages receive more attention than positive ones (Bolls, Lang, \& Potter, 2001; Lang, Bolls, Potter, \& Kawahara, 1999) supports the idea that different emotional tone messages are processed and memorized differently.

Therefore, the first question of this study will explore how the emotional tone of multimedia health information affects the perceived credibility of the 
source releasing the information. Moreover, the second research question will focus on how the emotional tone of the message influences the respondents' behavior of forwarding the information they have just received to their peers. Although there were no studies found related to how and why people forward messages to their peers, it is considered that this question will help elucidate which emotional tone message has a bigger potential to be accepted and disseminated voluntarily by the respondents to their friends, family and colleagues.

Furthermore, as can be noticed, the questions this study build on the notion of emotional tone, which is discussed in Annie Lang's model (Bolls, Lang, \& Potter, 1996; Bolls, Lang, \& Potter, 2001; Lang, 2000; Lang, Bolls, \& Kawahara, 1996; Lang, Dhillon, \& Dong, 1995) and thoroughly explored by Bolls, Lang, and Potter (2001). They all make a clear difference between the emotional tone, which is a characteristic of the message, and the emotional response, which is the audience's reaction to the message. Moreover, the third research question will identify how the negative or positive tone of the information presented in an online multimedia, audio-video, format affect comprehension by focusing on one of the three sub-processes discussed by the LC4MP model: encoding. This will be researched via a recognition/recall test.

Therefore, the LC4MP model is the most appropriate framework for this research that explores complementary filed of multimedia messages. 


\subsection{Defining concepts}

As said before, it is important to clearly define some of the basic notions that this study works with. These concepts come from different theories. Therefore, this subchapter explains the principles of source, credibility, reputation, source credibility and online source credibility, its closing section reviewing previous findings on health risk and benefit communication research.

\subsubsection{What is a source?}

Laswell (1948) is known to have created the communication equation by defining each element through a question. He was not only the first to make an ontological distinction of sources, but he is also responsible for the differentiation between message handlers and message controllers as well. As for the definition of source, he assumed that the source is the originator of communication implying that a source is what the source does. Figure 1 illustrates how Laswell understood the elements of the communication process.

Who? $\rightarrow$ Says what? $\rightarrow$ With what purpose? $\rightarrow$ On what channel? $\rightarrow$ And with what effects?

Source $\rightarrow$ Message $\rightarrow$ Intention $\rightarrow \quad$ Channel $\rightarrow$ Effects

Figure 1. Lasswell's communication process 
Judging his assumption according to the Oxford American Dictionary, he was right. There the source was initially defined as "the point of origin" or "the place from which something comes or is obtained" (Sundar \& Nass, 2001). A similar definition was implied by the early models of communication (Rogers \& Kinkaid, 1981; Shannon \& Weaver, 1949) without specifying any characteristics which led to a lack of conceptualization that limited the more current studies of the traditional (Newhagen \& Nass, 1989) and new media. Later on the Oxford American Dictionary introduced a revised definition for source describing it a person or book, etc. supplying information. A change was made as the definition of source shifted from its typical role designated and explained by the Source-Message-Code-Receiver (SMCR) models (Schramm, 1954; Shannon \& Weaver, 1949) to a more media-centric view.

A source can be different things. It can be for example the message itself or the channel through which the message is transmitted. "As Chaffee points out, receivers do not differentiate clearly between a person who generates a message (source) and one who relays a message that was created elsewhere (channel)" (Sundar \& Nass, 2001). For this reason, clarifying the notion of source and choosing the working definition of this research is essential. However, before it can be done, thorough reviews of both credibility and source credibility are needed. 


\subsubsection{What is credibility?}

According to Gaziano and McGarth (1986) the dimensions of credibility are trustworthiness, expertise, fairness, accuracy, factual rendering, lack of bias, and completeness of story. Credibility can, therefore, be translated as an automatic belief or trust in an information source. It refers to the degree to which an audience perceives the assertions made by a communicator to be the ones that the speaker considers valid (Pornitakpan, 2004). After reviewing a variety of publications in order to create an evaluation framework for assessing credibility for general computer use, Fogg and Tseng (1999) noted that scholarly reports suggest two terms as subcomponents of credibility: trustworthiness and expertise. In order to determine credibility, it is trustworthiness in conjunction with expertise that analysts should focus on, thus, this is the approach that the current research takes.

\subsubsection{What makes a source credible?}

\section{- defining source credibility -}

Sundar and Nass' (2001) article, shows that the concept of source credibility is as little defined as the source itself. According to them a source of a message can equally be "a person (e.g. Walter Cronkite), a group (e.g. a random sample of the U.S. population), an institution (e.g. the Supreme Court), an organization (e.g. the American Medical Association) or a label (e.g. 
conservative) that has a favorable or unfavorable connotation for the message recipient" (Sundar \& Nass, 2001, p. 53)

In fact, early discussions about source credibility and its influence on the effectiveness of communication were started notably by Hovland and Weiss (1951) who however confounded the source with the channel. Understanding credibility as a fundamental dimension in communication, their study compared well-known publications and well-known individuals ${ }^{1}$.

After considering the purpose and the nature of the research, Sundar and Nass' (2001) source definitions seemed the most appropriate to follow in this study. Consequently, it conceptualizes the source as "an institution originating information in a video format and making it available online via its own website". This will eliminate the confusion created by researches based on the SMCR model which affirms that each constituent of the scheme can be a source, and will focus the research on the specific respondents' perception of the information released by an institution that gathered, packed, and then released the information for dissemination purposes. Additionally, this research will conceptualize the medium as the Internet, the channel as the institution's own website on which the video messages are uploaded, and the receivers as the information seekers, namely individuals who watch the video released by the source-institution.

${ }^{1}$ Another conceptualization is as social representations (Moscovici, 1984) and for sure, there should be many other examples in the literature. 


\subsubsection{Taking source credibility online}

If defining source credibility in a classical environment might have seemed complex, things will get even more complicated when moving on the Internet. Burbules' (2001) study entitled "Paradoxes of the Web: The Ethical Dimensions of Credibility" showed that conventional methods of assessing credibility are not feasible on the Internet because of its complex features, speed, complex link structure, lack of referencing, and organizational conventions. The task of determining information credibility has become now in the consumers' responsibility and depends on their willingness to take the time and check the source of the data they view.

Factors such as trustworthiness, sponsorship and expertise, identified by Fogg and Tseng (1999) apply to the online medium as well, but added to them there are a series of sub-factors among which quick response, attribution of information to specific sources, listing of credentials, recurring uses, realworld addresses and contact information, and endorsement of the website by other media make a website and the information posted on it more credible (Fogg et al., 2002) can be mentioned. Online credibility is therefore different from the offline one. If the offline credibility ranged from presumed credibility to reputed credibility (Fogg \& Tseng, 1999), the online categories rely on or are influenced by content, operator or design (Fogg, 2003).

Although this research conceptualizes credibility as being operator-based, since it lies within the organization that owns the website, it is important to 
consider the difference between online perceived credibility and the official criteria of assessing online source credibility. Research (Eysenbach \& Kohler, 2002; Fox et. al., 2001; Morahan-Martin, 2004) shows that although health seekers are aware of the official criteria of assessing online credibility, they very seldom apply them. Rather, their perception of credibility is independent from the official source credibility assessment criteria and depends on other factors such as the information's consistency with what they know. This means, that health seekers may decide to trust some information they find online without actually checking all the specific sources, listing of credentials, recurring uses, real-world addresses, and contact information. Therefore, this study will focus on perceived credibility as the first research has already suggested.

\subsection{Health information online}

This section focuses on the findings of the literature on online health information. First, it looks at the characteristics of online health seekers with a special attention to youth and young adults that are the subject of this study. Second, the online communication of health risks and benefits is addressed.

\subsubsection{Online sources and the health information seekers}

In reality, most health seekers go online without a definite research plan (...) And about one third of health seekers who find relevant information online bring it to their doctor for a final quality check (Fox \& Lee, 2002). 
The evolution of the Internet might explain in part its current popularity and the fact that it is nowadays hosting such a big variety of types of information. Once companies and organizations realized the Internet's potential, sometime in the beginning of the 1990s, an unprecedented competition for attention of the Internet users has begun. On the other hand, as a result of this competition, Internet users have become more aware of the immense information potential that the Internet represents and of the fact that companies and interest groups observed the same fact.

In 2002, Fox and Lee (2002) attached a concrete number attached to the popularity of seeking health information online; they estimated that about 6 million Americans go online for medical advice on a typical day. It means that more people go online for medical advice on any given day than actually visit health professionals according to the figures provided by the American Medical Association (Fox \& Lee, 2002). One of the reasons why 93\% of the respondents said they go online is that the Internet provides them with the opportunity of viewing that information at a time which is convenient for them. The Internet is also preferred when it comes to getting information about sensitive health topics: $16 \%$ of the health seekers named this as their main reason for online queries (Fox et al., 2001). Therefore, the internet has not only become a medium where people can get second opinions, but it has also grown into being a tool for family members to seek help for ailing loved ones and friends. 
Interestingly, there is a clear difference gender behavior online. According to the same study of Fox et al. (2001) "women are much more likely than men to seek online health information. Women are more likely to register strong feelings about the benefits of online searches, especially those related to the wealth of information online and the convenience of online searches" (p. 6). On the other hand "Men are more likely to be seeking material about what happens to someone during an illness and when certain treatments or drugs are administered" (p. 6).

Besides gender discrepancies, previous research has also shown that there are behavioral differences between what people say they do in terms of assessing the credibility of a website and what they really do (Eysenbach \& Kohler, 2002). Most health seekers declared that they move away from a website if it looks too commercial or seems more concerned with selling products than providing accurate information (Fox \& Lee, 2002; Richardson, 2003) or if they cannot identify the source. Lack of information about the last update, no visible seal of approval, and sloppy or unprofessional designs are other factors that decrease the credibility of an online message and lead to the closing of the page that hosts it. However, although health seekers know what they have to do in order to check the information they access online, none of them is actually checking the "about us" sections of websites, disclaimers, or disclosure statements. Moreover, very few actually remember from which 
websites they had retrieved information (Eysenbach \& Kohler, 2002; Morahan-Martin, 2004).

\subsubsection{Youth and young adult health information seekers}

Compared to the whole group of online health seekers, the youth and young adults are most certainly those being more accustomed to using the Internet as an information source as well as those with probably the highest access rates. A study undertaken in Nottingham, UK showed that $100 \%$ of the respondents had access to Internet at school and $78 \%$ had access elsewhere as well (Goold, Ward, \& Carlin, 2003). Similar results regarding the Internet access were obtained in the United States as well. According to Kaiser Family Foundation $75 \%$ of today's youth having used, at some point, the Internet to look up some health information, "24\% of people 15-24 years old having reported using it "a lot" for this purpose" (Kanuga \& Rosenfeld, 2004, p. 118). Unlike the general group of online health information seekers, the primary reason of youth and young adults for searching health information online is to address their questions related to sensitive health topics. Sexuality ranking number one and STDs as number six among the topics that adolescents of grades 10-12 report as making them too embarrassed, afraid or uncomfortable to discuss with their health care provider, parents or peers (Ackard \& Neumark-Sztainer, 2001). Based on this need of information and on the many studies about adolescents' use of Internet for searching health information 
(Borzekovski \& Rickert, 2001; Rideout, 2001; Hansen et. al, 2003; Hanauer et al., 2004;) specific health teenage information websites such as teeanagehealthfreak (www.teenagehealthfreak.com), teenhealthfx (www.teenhealthfx.com) or coolnurse (www.coolnurse.com) were created. Once some of the questions about accuracy of information and content design were answered, the websites were reviewed by physicians and written in a style that was proven to be accessible to teenagers. Moreover, judging after the first date of registered copyright of the websites - 1999 for teenhealthfx and 2000 for coolnurse - and the big numbers of anonymous questions received, the websites reached their objective: to disseminate accurate health information to teenagers via Internet, emphasizing risks and benefits of behaviors, medication, and medical consultations. The next step in this process is to find out how to communicate those risk and benefits to youth and young adults effectively. It is with this with which this research id concerned by focusing on a major interest for them, the HPV vaccine. It presents information in a multimedia format, through such increasingly popular online web sites like YouTube or Google Video that have an enormous number of subscribers and which also make the uploaded videos available for embedding. 


\subsubsection{Risk and benefits}

\section{- communicating immunization information online -}

The HPV vaccine is the newest and the only immunization method available against Human Papillomavirus infections with the high-risk strains 16 and 18, that are responsible for $70 \%$ of cervical cancers, and the low-risk strains 6 and 11, that cause 90\% of genital warts cases (Merck, 2007). This is the closest medicine could get to the public's desire of having a vaccine that would protect $100 \%$ against genital warts and $75 \%$ against cervical cancer (Hoover, Carfioli, \& Moench, 2000). Studies have been undertaken to determine females', youth's, young adults' and parents' attitudes towards the acceptability of a potential HPV vaccine (Dempsey et al., 2006; Hoover, Carfioli, \& Moench, 2000; Kimmel \& Wolfe, 2005; Zimet et al., 2000). They revealed concerns similar to those related to consecrated vaccines against diphtheria, tetanus and acellular pertussis (DTaP), measles, mumps and rubella (MMR), varicella or hepatitis B: safety was the first issue brought into discussion (Kimmel \& Wolfe, 2005). Furthermore, the HPV vaccine faces the same general barriers as every other immunization: "problems of access to medical care, lack of knowledge about the vaccine or target disease, and fears about vaccine safety" (Kimmel \& Wolfe, 2005, p.S19) and such misconceptions as believing that instead of strengthening the immune system many vaccines are weakening it, and that vaccines might cause chronic diseases such as asthma, autism, diabetes mellitus or multiple sclerosis. 
Due to the young age at which the vaccine is advised to be administered, several misconceptions were discovered through and infirmed by research. The most common of these refers to the decrease in responsible sexual behavior. The participants of the study of Kahn et al. (2003) reported that after vaccination with the HPV vaccine they would not feel safe engaging in high-risk sexual behaviors such as having multiple sex partners and having sex without using condoms.

Additionally, information about vaccine acceptability influencers was made available, indicating a series of strategies that health practitioners could consider in order to overcome the factors that negatively influence the acceptability of a vaccine (Ball, Evans, \& Bostrom, 1998; Dempsey, Zimet, Dacis, \& Koutsky, 2006). The influencers are the cultural, religious and personal backgrounds of the person consenting for the vaccine administration, the preference for taking voluntary and controllable risks versus involuntary ones based on the belief that without any vaccination the disease can be prevented, the preference for assuming natural risks than man-made ones the main argument being that immunity acquired after natural infection is preferable to the one induced by the vaccine, peer groups, the physicians' recommendation, the amount of dread and fear the disease provokes, the memorability of the pro or cons vaccination messages, and the way the message is framed (Ball, Evans, \& Bostrom, 1998). 
As a consequence, this study has been designed with the need of having credible online health sources as well as the necessity of knowing how to develop effective and memorable health information messages that would, the same time, enhance the credibility of the source releasing them in mind. 


\section{\& CHAPTER 2 d}

Chapter 2 presents the methodology of this research, explaining its choice. It also describes the research design and outlines the independent and dependent variables, and the participant recruitment procedure.

\subsection{Methodology}

This study is going to use an online controlled experiment in order to answer the research questions. The reason why an experiment was chosen is because experiments are the best to test causal relationships such as the influence a source has on the perceived credibility of the information, and the influence of the emotional tone of the information on comprehension. Also, experiments represent "the most powerful method of seeking answers to research questions about cause and effects" (Grabe \& Westley, 2003).

Moreover, the choice of an online format is also due to the recent research trends where $3.6 \%$ of the online research undertaken in the last years is represented by experiments (Weaver, 2002) and to the nature of research questions this study poses. Furthermore, the advantages of this method lie in the lack of geographic limitations, permitting for the testing of national and international samples as well as in the possibility of faster data collection compared to laboratory experiments. Added to this is the possibility of 
downloadable data, both for the subjects and for the researcher. The drawback that such an experiment poses and which the researcher had to address in the research design is the honesty of the subjects and their bias towards the medium (Pornitakpan, 2004; Shon, Marshal, \& Musen, 2000; Simons, Berkovitz, \& Mayer, 1970; Slater \& Rouner, 1996). These two though can be overcome by introducing checking questions so as to verify the coherence of each subject's answers.

\subsection{Research design}

This online experiment consists of a 2 (source) x 3 (emotional tone) model design. While the source variable was manipulated between subjects, the emotional tone was a within subjects variable. This enabled the researcher to use the same multimedia messages and attribute them to two different sources, which allowed a bigger control over the experiment as well as it kept the experiment simple and easy to understand for participants. Moreover, if a respondents' bias existed towards one source, it was eliminated due to the between subjects design. On the other hand, having the emotional tone as a within subjects variable, gave the researcher a clearer picture of the treatment effects as the variance within treatments was significantly reduced by having each subject in each condition (Reeves \& Geiger, 1994).

The experiment was presented in the form of a questionnaire that is based on information comprised in three different multimedia messages. 
Participants viewed the messages attributed to one source: either a pharmaceutical company or a governmental health agency. Subjects came from one age group: they all belong to the youth and young adult, group between 18-35 year olds, not because they are thought to process the information they are presented differently but because they represent one of the most active age online. They also came from one gender group, females. Moreover, females aged 18-26 are the secondary target of the HPV vaccine and the remaining segment of the group in the 27-35 range age group are targeted by marketers as the mothers of potential consumers. The multimedia messages and the complete questionnaire were uploaded on Survey Artisan (www.surveyartisan.com), an online survey builder and data collection instrument, providing the environment for both the design and administration of the questionnaire.

\subsection{Independent variables}

Source. Source was conceptualized as "an institution originating information in a video format and making it available online via its own website" (Sundar \& Nass, 2001). Two institution types were used: a pharmaceutical company and a governmental health agency.

Emotional tone. Emotional tone was conceptualized as the multimedia message content that evokes a specific pattern of emotional response defined as positive, negative, or coactive. Emotional tone is a feature of the message 
and not a reaction of the respondent. Studies used this concept to investigate how more or less arousing messages affect the message processing and their memory (Bolls, Lang \& Potter, 2001; Lang et al., 1999). In order to assess whether the emotional tone considered by the researcher coincides with the respondents' perception, respondents were asked to rate twice each multimedia message, once in terms of pleasantness and another time in terms or unpleasantness. A 9-scale differential was used, its purpose being not only to identify the perceived emotional tone of each multimedia message, but also to ascertain that the respondents' self-report of respondents is consistent.

Demographics. Three demographic variables were collected: age, race and education. Taking into account that all respondents come from the same university campus located in the United States, the researcher considered as more important to control for the differences among age groups, races and education levels than among nationalities and/or places of origin.

\subsection{Dependent variables}

Perceived credibility. Participants' perceived credibility of sources was measured using the McCroskey source credibility scale, which is a 12 item 7-point semantic differential scale. Since the scale was previously used to assess the credibility of a message sidedness and evidence, and since it had on every occasion both high validity and high reliability indexes, it also allowed to 
explore two source credibility dimensions: authoritativeness and character (Rubin, Palmgreen \& Sypher, 1994).

The bipolar constructs were: reliable/unreliable, uninformed/informed, unqualified/qualified, intelligent/unintelligent; valuable/worthless, inexpert/expert, honest/dishonest, unfriendly/friendly, pleasant/unpleasant, selfish/unselfish, awful/nice, and virtuous/sinful.

Comprehension/memory. Comprehension of the message content was measured as an indicator of how well stimulus messages were encoded into short-term memory. Message comprehension was tested by presenting participants with short statements which were either included in or omitted from the previously viewed multimedia messages. Respondents were instructed to indicate as quickly as possible whether or not they believe the statement was from one of the messages they have viewed before. They were provided with a choice of true/false.

\subsection{Participants and procedure}

Participants of the experiment were females, aged 18-35. Participants were recruited among students, faculty and staff of the University of MissouriColumbia through academic unit email list serves. Participants completed the study by accessing an online website: www.missouri.edu/ aay59/consent.htm.

Once accessing this page, participants were first presented with a consent form to read and opt in or out of the experiment. The consent form contained 
a short description of the general purpose of the experiment saying that it investigates how youth and young adult women respond to different forms of public health information. If they chose to take part in the experiment, participants were asked to give information on their gender and age, only those falling into the age group of interest were considered relevant for this experiment. Once they elected "female" and "18-35", respondents were given the option to choose a number from one to six, which took them to a different questionnaire hosted by Survey Artisan. Given that Survey Artisan does not allow in-questionnaire randomization, offering to the respondents the opportunity to choose a survey number made it possible to obtain the same randomization effect. Survey Artisan controlled the presentation of all study instructions, stimulus messages, and dependent measures. The first screen viewed introduced participants into the questionnaire of their choice, the following screen explained that they were going to view a multimedia message, about which they would be asked to answer a number of questions.

In the next step, Survey Artisan presented each stimulus message that was immediately followed by questions about the pleasantness/unpleasantness of message, the McCroskey perceived credibility scale and the self-declared forwarding behavior. Sources were identified by their generic names, namely "a governmental health agency" and "a pharmaceutical company”. Message texts were created by the researcher, as were the multimedia messages so as to keep as many variables as possible 
under control. Since the source treatment was randomly assigned within respondents, participants viewed only one source and 3 message types, therefore the same video bites could be used in each case, but different sources were assigned to them in the video's introductory statement.

After viewing the video, the respondent was first asked to report how pleasant/unpleasant she found the message that has been presented in order to measure the accuracy of the emotional tone. Next, they were asked to evaluate the credibility of the information received using the semantic multidifferential scale of McCroskey, based on the bipolar constructs situated on a 7-point scale. The third question, in an attempt of linking the emotional tone of the message with the forwarding behavior, aimed at finding out to how many people would the respondents forward the information they have just viewed. The self-report question was then repeated, with its formulation being changed to the other pole: if respondents had been first asked how pleasant they found the information, the second self-report question asked them how unpleasant they considered the same information to be. The same questions were asked for each of the three treatments. Afterwards, a 3 minute video distracter was afterwards administered.

The second part of the questionnaire represented a recognition test and it offered information to respondents, in form of a series of written sentences, on the risk and benefits of the HPV vaccine that had been either included or not in the previous multimedia messages. Respondents were asked to determine 
whether or not they heard those statements before. Upon the completion of the comprehension test, participants were asked to state their age, race and their current level of studies. Finally, a debrief concerning the details of the study and a link to the official page of CDC about the HPV were offered, and respondents were thanked for their participation. 


\section{\& CHAPTER 3 \&}

This chapter presents the findings of the experiment. It shows statistical results regarding each of the three research questions posed.

\subsection{Manipulation check}

A manipulation check was performed on the perceived pleasantness and unpleasantness of the emotional tone by calculating the difference between the pleasantness and unpleasantness scores for each type emotional tone message. Pairwise comparisons were submitted with the differences obtained. Results showed that there was a successful manipulation of the positive (mean -.367) and negative (mean -2.013) emotional tones, as the messages were rated significantly different by the participants of the experiment. However, the coactive (mean -1.320) and negative messages did not obtain significantly different scores, the manipulation of the coactive emotional tone being thus unsuccessful. Table 1 shows the pairwise comparisons between the three emotional tone messages. 
Table 1 - Emotional tone pairwise comparisons for manipulation check

\begin{tabular}{|c|c|c|c|}
\hline $\begin{array}{c}\text { Emotional } \\
\text { tone } \\
\text { (A) }\end{array}$ & $\begin{array}{c}\text { Emotional } \\
\text { tone } \\
\text { (B) }\end{array}$ & $\begin{array}{c}\text { Mean } \\
\text { difference } \\
(A-B)\end{array}$ & p. \\
\hline \multirow[t]{2}{*}{ Positive } & Coactive & $\left..9533^{*}\right)$ & .003 \\
\hline & Negative & $\left.1.647^{*}\right)$ & .000 \\
\hline \multirow[t]{2}{*}{ Coactive } & Positive & $-.953\left(^{*}\right)$ & .003 \\
\hline & Negative & 0.693 & .146 \\
\hline \multirow[t]{2}{*}{ Negative } & Positive & $-1.647\left(^{*}\right)$ & .000 \\
\hline & Coactive & -0.693 & 0.146 \\
\hline
\end{tabular}

\subsection{McCroskey scale reliability check}

A reliability check of the McCroskey perceived credibility scale was performed for authoritativeness and character dimensions as well by calculating Chronbach's Alpha for each emotional tone. Results showed that the scale is very reliable for the perceived authoritativeness of positive (Chornbach's Alpha $=.865)$ and negative (Chornbach's Alpha $=.891)$ messages. Similar results were obtained for the perceived character of all messages: positive (Chornbach's Alpha $=.792$ ), negative (Chornbach's Alpha $=.734)$ and coactive (Chornbach's Alpha $=.846)$. The scale was not reliable for measuring the perceived authoritativeness of coactive messages (Chornbach's Alpha $=$-.475). Table 2 presents Cronbach's Alpha for both credibility dimensions. 
Table 2 - Chronbach's Alpha for perceived credibility dimensions

\begin{tabular}{|c|c|c|}
\hline $\begin{array}{c}\text { Emotional } \\
\text { tone }\end{array}$ & $\begin{array}{c}\text { Chronbach's Alpha } \\
\text { for } \\
\text { authoritativeness }\end{array}$ & $\begin{array}{c}\text { Chronbach's Alpha } \\
\text { for } \\
\text { Character }\end{array}$ \\
\hline Positive & .865 & .792 \\
\hline Negative & .891 & .734 \\
\hline Coactive & -.475 & .846 \\
\hline
\end{tabular}

\subsection{Research question 1}

The first research question focused on how the emotional tone of an online multimedia message influences the perceived credibility of its releasing source. The emotional tone affects significantly both the perceived authoritativeness $(F(2,308)=41.225, p<.000$, eta squared $=.211)$ and the perceived character $(F(2,308)=6.911, p<.000$, eta squared $=.043)$. This indicates that there is a main effect of emotional tone on the perceived credibility of a source. Table 3 shows that people perceive sources releasing coactive messages as the least authoritative, while those releasing negative messages as having less character. Additionally, post-hoc analysis revealed that there are significant differences in the perception of positive and coactive messages as well as that of negative and coactive messages. However, no significant difference was found between positive and negative messages. Table 4 shows these findings for pairwise comparisons based on the mean differences and the $p$ values. 
Table 3 - Means for perceived source credibility according to the emotional tone of the message

\begin{tabular}{|c|c|c|}
\hline Emotional tone & $\begin{array}{c}\text { Authoritativeness } \\
\text { mean }\end{array}$ & Character mean \\
\hline Positive & 5.042 & 4.314 \\
\hline Negative & 4.896 & 4.269 \\
\hline Coactive & 4.297 & 4.040 \\
\hline
\end{tabular}

Statistical analysis also showed that the emotional tone of a message had a more powerful effect on the perceived authoritativeness of a source (eta squared $=.211)$ that on its perceived character (eta squared $=.043)$. Moreover, data demonstrated that the source, be it a pharmaceutical company or a governmental health agency, did not influence the perceived credibility.

Table 4 - Pairwise comparisons between the positive, negative and coactive emotional tones

\begin{tabular}{|l|c|c|c|}
\hline \multirow{2}{*}{$\begin{array}{c}\text { Emotional tone } \\
\text { (A) }\end{array}$} & $\begin{array}{c}\text { Emotional tone } \\
\text { (B) }\end{array}$ & $\begin{array}{c}\text { Mean Difference } \\
\text { (A-B) }\end{array}$ & p. \\
\hline \multirow{2}{*}{ Positive } & Coactive & $\left..7444^{*}\right)$ & .000 \\
\hline \multirow{2}{*}{ Coactive } & Negative & 0.145 & .135 \\
\cline { 2 - 4 } & Positive & $-.744\left(^{*}\right)$ & .000 \\
\hline \multirow{2}{*}{ Negative } & Negative & $-.599\left(^{*}\right)$ & .000 \\
\cline { 2 - 4 } & Positive & -0.145 & .135 \\
\hline${ }^{*}$ The mean difference is significant at the .05 level. & $.599\left(^{*}\right)$ & .000 \\
\hline \multicolumn{2}{|l}{} \\
\cline { 2 - 4 }
\end{tabular}




\subsection{Research question 2}

The second research question investigated how the emotional tone of a message influences the respondents' behavior of forwarding the message to their peers. Data showed that the emotional tone was influential on people's willingness to forward the message. Coactive $($ mean $=5.54)$ and positive $($ mean $=5.22)$ messages are more likely to be forwarded than the negative $($ mean $=3.74)$ ones. Table 5 shows the paired sampled correlations for the willingness to forward positive and coactive messages, and positive and negative ones. Due to the skewness of the data computing an average for the number of people to whom the messages would be forwarded in each of the three categories is not sensible.

Table 5 - Paired sampled correlations of respondents' willingness to forward a message having a different emotional tone

\begin{tabular}{|c|c|c|c|}
\hline Correlated pair & N & Correlation & p. \\
\hline Positive - Coactive & 161 & 0.926 & .000 \\
\hline Positive - Negative & 159 & 0.798 & .000 \\
\hline
\end{tabular}

\subsection{Research question 3}

The third and final research question focused on whether or not there is a difference in how messages of positive and negative tones influence people's comprehension. A paired sample T-test analysis demonstrated that there was a significant difference between how people recognize, and thus comprehend, negative and positive messages $(F(1,131)=16.458, p .<.000$, eta squared $=$ 
.112 ). In addition, risk messages (mean $=.814$ ) were better recognized than benefit statements $($ mean $=.759)$. 


\section{\& CHAPTER 4 \&}

This chapter will focus on the discussion of this experiment's results. It will emphasize the implications of this research and its drawbacks as well as it will identify potential questions that future research could address.

\subsection{Discussion}

Prior to analyzing the data, a manipulation check was run in order to verify the accuracy of the emotional tone design. The pairwise comparisons submitted showed a successful manipulation only of the positive and negative emotional tones. The comparison between negative and coactive emotional tones revealed that there was no statistically significant difference in the way respondents perceived the two, one of the factors influencing this result being attributed to the novelty of the topic and to the respondents' lack of knowledge about the issue. Moreover, looking at the mean scores of all three emotional tones, none of them was perceived as clearly pleasant and positive: positive tone mean -.367 , negative tone mean -2.013 and coactive tone mean -1.320 ; showing once again that the novelty of the HPV vaccine influences the respondents' perception of the emotional tone of a message.

Results of this research also demonstrate the validity of using the McCroskey perceived credibility scale for assessing the perceived credibility of 
sources releasing positive and negative messages. The results also showed that for coactive messages the scale is not reliable, two of the six terms used to define the perceived authoritativeness have negative loadings. This means that the more reliable, qualified, valuable and expert a source is perceived, the less informed and intelligent it appears to the people it addresses. There are several reasons that could have caused this scale bipolarity, the lack of attention paid by respondents to the either the questions posed or to the scale itself due to their desire to finish the experiment as quickly as possible, the respondents" consideration of the McCroskey scale as being irrelevant and not linked to the topic they seeing, and the novelty of the information presented about the risks and benefits of the HPV vaccine.

This latter reason is also supported by the lowest mean scores for perceived authoritativeness obtained by each of the sources releasing coactive messages: 4.227 for the pharmaceutical company and 4.368 for the governmental agency. Furthermore, the results show that people are more confused when receiving dual messages from pharmaceutical companies or governmental health agencies, respondents clearly perceiving as more authoritative the clear positive messages. Therefore, according to the data gathered, emotional tone influences the way a source is perceived. This also suggests that governmental agencies or pharmaceutical companies who wish to be perceived as more authoritative should choose to communicate only positive messages. Since having pharmaceutical companies communicate only 
positive messages is not legally allowable and since communicating health related information requires the listing of both risks and benefits, a more careful consideration should be given to coactive messages, their content, context and formulation.

Results also showed a lack of statistically significant differences between how respondents perceived the sources releasing positive and negative messages. While the coactive messages played against the sources' perceived authoritativeness presenting them as undecided, people had similar weak feelings towards pharmaceutical companies or governmental health agencies communicating either only the risks or only the benefits of the vaccination with the HPV vaccine. This insignificant change in attitude towards the source that releases positive or negative messages can be explained by having respondents' either used to or expecting pharmaceutical companies or governmental health agencies to take a clearer positive or negative stance when addressing the public.

Data also showed that emotional tone also affects the perceived character of a source, by character understanding honesty, friendliness, pleasantness, unselfishness, niceness and virtuosity. As in the case of assessing the perceived authoritativeness of a source, a repeated measures ANOVA analysis was submitted, results demonstrating that there is a significant difference between how people perceive sources releasing negative messages compared to positive ones as well between coactive compared to negative statements. The analysis 
also outlined the lack of statistical differences between the character perception of sources releasing positive compared to coactive messages. This shows that, as in the authoritativeness case, coactive messages confuse respondents. Additionally, the between source mean scores comparison highlighted an interesting difference: that the character of a pharmaceutical source is perceived better when emitting positive messages while the same effect is obtained by the governmental health agency when transmitting coactive messages. According to these results, governmental health agencies could consider transmitting coactive message when they are looking to improve their character scores whereas pharmaceutical companies should stick to the positive messages, as those bring them the highest scores for both authoritativeness and character.

Results also revealed that the emotional tone has a bigger impact on the perceived authoritativeness of a source than on its perceived character, the eta squared (.211) for the perceived authoritativeness being significantly bigger than the one for the perceived character (.043). This means that a different emotional tone influences more how people perceive a company as being more or less reliable for example than as being more or less honest. In the context of the present research, where each message was designed as a 30 second information video byte that presented either only risks, only benefits or both of the vaccination with the HPV vaccine, this shows that authoritativeness is a dimension that more linked to the content of the message whereas character is 
more linked to the source itself, being prone to be influenced by the subjects' knowledge about the company, the issue under discussion as well its attitudes towards both.

Looking at the results answering to the second research questions, the one about the emotional tone and its influence on the respondents' forwarding behavior, the data obtained cannot be generalized. Almost half of the respondents ( $42 \%$ for the positive message, $48 \%$ for the coactive and $49 \%$ for the negative one) declared that they would not forward any of the messages. Although their unwillingness to forward a recently acquired piece of information might seem irrelevant, if linked to the controversial topic of the newly released HPV vaccine there are several reasons that could explain the respondents' reaction: their little knowledge about the HPV vaccine, their religious background, their misconceptions about vaccines or their misconceptions about pharmaceutical companies and governmental agencies as being corrupt. As this research cannot verify either of these suppositions, further research could explore them.

Out of the other $50 \%$ of respondents that indicated a number of people to whom they would forward the messages they have seen, approximately $1 \%$ of the respondents' chose to forward the message they have just seen to 45 to 200 people. Although it is not impossible, the researcher believes that it is highly probable that someone has at hand at least 45 e-mails addresses. It is believed therefore, that these people either typed incorrectly the numbers, such as 45 
could have been 4 to 5 people, or 200 could have actually been 20 or just added the number of people they know but did not think whether they actually have all the e-mails they would need. However, the fact that such extreme numbers were registered, could also indicate that these people perceived the messages relevant and worthy to be shared with all or most of their peers.

Excluding the two extremes, those that would not forward any of the messages and those who would forward them to all their friends, the remaining $49 \%$ of the answers still has a skewed distribution. Nevertheless, most of these respondents would forward the positive (12.7\%) and coactive (10.6\%) messages to 5 people and the negative one (10.9\%) to only 2 people. Therefore, it can be concluded that positive messages have the biggest chances to be forwarded. Considering this and the results regarding the perceived credibility of a source, it can be stated that pharmaceutical companies are not only better perceived when they release positive messages, but the chances that their messages are forwarded to their peers by youth and young adult targets increase.

The third and last research question focused on the difference in comprehension that negative or positive nature of the message might cause. The data obtained showed that risk information was better remembered than benefit statements, results which are similar to those obtained by researches Bolls, Lang \& Potter (2001) and Lang et al. (1999). 
Originally, these findings on the comprehension of messages modify the recommendations that the previous two research questions inspired. It was suggested that coactive messages containing new information on new topics are confusing for the youth and young adult public. It was also suggested that both pharmaceutical companies and governmental health agencies should stick to releasing positive messages in order to facilitate the spreading of their messages between peers and achieve high credibility. While these suggestions seem to be contradicting the results of the third research question, due to the nature of the data, the current research cannot resolve this discrepancy. However, it would be instrumental to understand that if people remember better the risk information, how a company could communicate with its publics, knowing that its credibility is affected when sending negative information, second, whether there is a relationship between risk recognition and message forwarding behavior. Third, how, if at all, coactive messages could improve the recognition of risk and benefit statements. And finally, whether coactive messages could improve the recognition of risk and benefit statements and the perceived credibility of a source and questions could go on.

Due to the fact that this research did not address the recognition of risk and benefits contained in both negative and coactive messages, respectively in positive and coactive statements, nothing can be said about the comprehension of coactive information nor can any potential relationship between the emotional tone of the message be inferred, its recognition, and its 
impact on the perceived credibility of the source. However, these could also be of interest for future research.

Additionally, following the pattern suggested by Annie Lang's LC4MP model (2006), messages referencing risks are activating the respondents' aversive system while messages discussing benefits would activate the respondents' appetitive system. Furthermore, it was considered that coactive messages would activate both systems. Moreover, it was assumed that negative messages should be making reference to risk information while positive messages were benefit statements. What research revealed is that risk information is not necessarily perceived as negative, failing therefore to activate the desired aversive system. This means that respondents perceive the risk information as something that they need to know and no need to fear, failing to perceive the danger that the source wants them to see. Moreover, there is information that the source regards as a positive message and a benefit for the receiver that the respondents might perceive as unclear and that therefore activated their aversive system. Therefore, further research could explore the differentiation between positive/benefit messages activating the appetitive system and positive/benefit messages activating a protection reaction from the respondents. The same implications and differentiations could be studied between negative/risk messages activating either one of the two systems. In addition, attention to the degree of perceived risk or benefit should be studied. 
Finally, there are elements of this experimental design that can be improved in order to enhance future research. For example, participants should be given a unique experiment ID. The present research was online and did not have such a feature which could prevent respondents to take the experiment more than once. Questions regarding perceived credibility should be treated in a setting different from the ones focusing on recognition. The messages of the present research followed the definitions of coactive, positive and negative messages so that they can be used for the recognition test; however, the information presented in each of them had to be different. In other words, it would be interesting to see whether the emotional tone would have the same impact on the perceived credibility of a source if the messages were containing the same information but they would be phrased differently. Moreover, collecting such demographics information as religious affiliation and more detailed education level information, would help find out whether and to what extent the forwarding behavior and credibility perception are influenced by peer groups, family and church, and whether the influence is different for freshmen, sophomores, juniors and seniors. Additionally, offering an incentive would certainly ease data collection. 


\section{\& CHAPTER 5 \&}

The present chapter states the conclusions of this study by restating the research questions, the results obtained and the main discussion points presented in Chapter 4 .

\subsection{Conclusions}

Inspired by the need of Public Relations practitioners to create messages with increased effectiveness and by the same demand from their clients, this study used the newly released HPV vaccine as a pretext to investigate the effect of different emotional tones on the perceived credibility of a source and the respondent's willingness to forward the message to their peers. It also looked at the differences in comprehension regarding risk and benefits statements that were comprised in positive and negative messages. After reviewing the literature related to online health information seeking, defining the concepts of source, source credibility, perceived source credibility and online credibility and presenting the theoretical framework of the research, the Annie Lang's LC4MP model (Lang, 2006), the paper succinctly presented the methodology and thoroughly discussed the results. Among the most interesting findings is the fact that the emotional tone influences the way people perceive the sources of the messages: positive messages had a positive, while coactive messages had 
a negative impact on source credibility. Also, data showed that there were no significant differences between the credibility scores of the two sources. Results also outlined the fact that positive messages are more likely to be forwarded to a bigger number of people and that risk statements are better recognized than the benefit ones.

The present research made a valuable contribution to understanding of the influence that the messages' emotional tone has on the perceived credibility of a source and the forwarding behavior of the message recipients. Moreover, this study challenged one the most valid and reliable perceived source credibility scales, by showing that coactive messages lead to negative term loadings. Finally, it outlined the importance of researching coactive messages more thoroughly, suggesting emotional tone, order, context, issue and source manipulations. 
Appendix 1 - Multimedia messages text

\section{POSITIVE}

Getting vaccinated with Hexil has many advantages. For instance, once vaccinated the immune system will be able to fight those strains of the HPV virus that cause the most cases of genital warts. Moreover, by not getting infected with HPV virus the chances of developing abnormal cell formation and lesions are substantially reduced not to mention that those taking the vaccine will be protected against one of the most common sexually transmitted diseases of the century.

\section{NEGATIVE}

Getting vaccinated with Hexil has some risks. For instance, Hexil was designed to protect against the HPV virus strains that were proven to cause the most damage. But this leaves the patient exposed and unprotected against the other remaining 90 strains of the virus. Moreover, taking the vaccine might have secondary effects such as vaginal discharge, itching, sores and even bleeding. Also, for a short period of time, the patient may experience pain during intercourse. 


\section{COACTIVE}

Getting vaccinated with Hexil has both risks and benefits. Clinical tests have revealed that patients may experience swelling or redness at the injection site as well fever, nausea, dizziness and vaginal bleeding. But being vaccinated with Hexil will not weaken the immune system, it will not lead to the formation of any abnormal cells and it certainly will not block the vaginal, urethral or anal openings. However, Hexil will not prevent patients from getting pregnant nor will it not protect them against other sexually transmitted diseases. 
BEGIN :

You are going to view a short multimedia message about the HPV vaccine. The message, presented by the CEO of the pharmaceutical company producing it, was uploaded on the company's website. After viewing the message, please answer the questions that follow.

Please click the "play" button and wait for the multimedia file to load.

35. How pleasant did the message you just viewed make you feel?

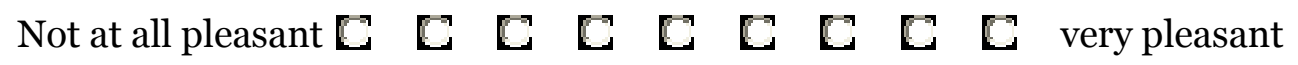

35. After viewing the previous message, you find the pharmaceutical company as being a source:

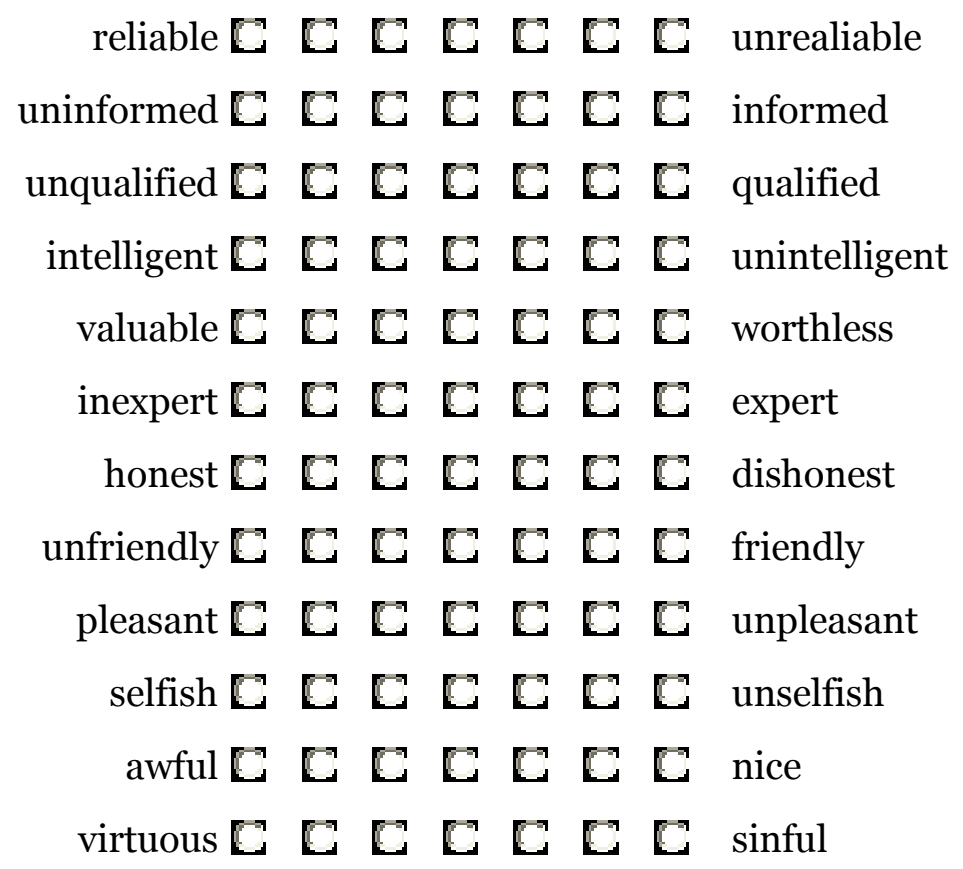

35. How unpleasant did the message you just viewed make you feel? 


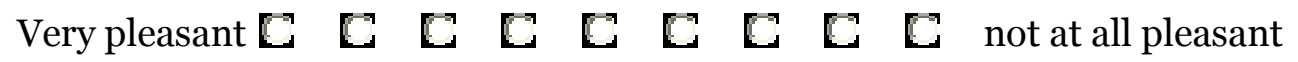

35. Please think of the people that you might possibly forward this message to. Please indicate how many people you would be willing to forward this message to.

You are going to view another short multimedia message about the HPV vaccine. The message, presented by the CEO of the pharmaceutical company producing it, was uploaded on the company's website. After viewing the message, please answer the questions that follow.

Please click the "play" button and wait for the multimedia file to load.

5. How unpleasant did the message you just viewed make you feel?

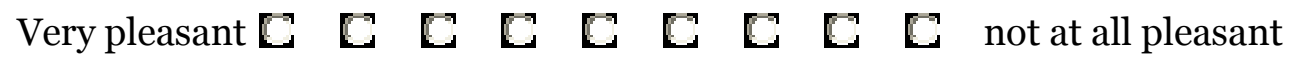

6. After viewing the previous message, you find the pharmaceutical company as being a source:

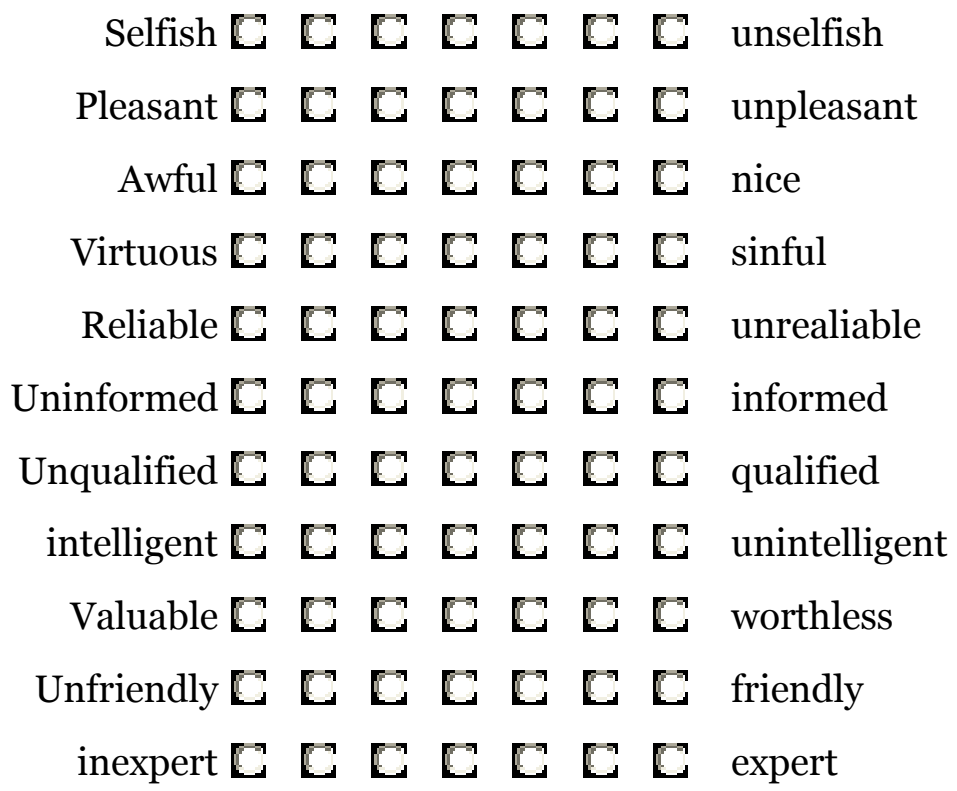


7. How pleasant did the message you just viewed make you feel?

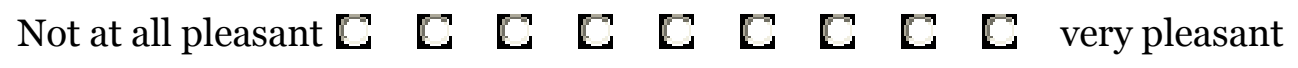

8. Please think of the people that you might possibly forward this message to. Please indicate how many people you would be willing to forward this message to.

You are going to view another short multimedia message about the HPV vaccine. The message, presented by the CEO of the pharmaceutical company producing it, was uploaded on the company's website. After viewing the message, please answer the questions that follow.

Please click the "play" button and wait for the multimedia file to load.

9. How unpleasant did the message you just viewed make you feel?

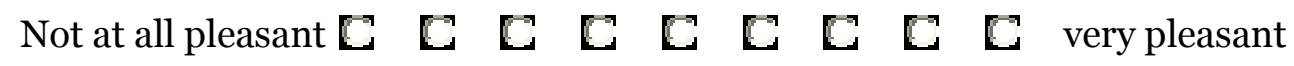

10. After viewing the previous message, you find the pharmaceutical company as being a source:

$$
\begin{aligned}
& \text { valuable } \mathbb{C} \mathbb{C} \mathbb{C} \mathbf{C} \mathrm{C} \text { worthless } \\
& \text { unfriendly } \mathbf{C} \mathbf{C} \mathbb{C} \mathbf{C} \mathbf{C} \text { friendly } \\
& \text { inexpert } \mathbb{C} \mathbb{C} \mathbf{C} \mathbb{C} \mathbf{C} \text { expert } \\
& \text { honest } \mathbb{C} \mathbb{C} \mathbb{C} \mathbb{C} \text { dishonest } \\
& \text { selfish } \mathbf{C} \mathbb{C} \mathbb{C} \mathbb{C} \text { unselfish }
\end{aligned}
$$

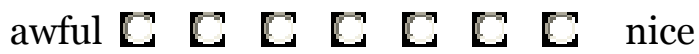

$$
\begin{aligned}
& \text { virtuous } \mathbb{C} \mathbb{C} \mathbb{C} \mathbb{C} \text { sinful }
\end{aligned}
$$




$$
\begin{aligned}
& \text { reliable } \\
& \text { uninformed } \\
& \hline
\end{aligned}
$$

11. How pleasant did the message you just viewed make you feel?

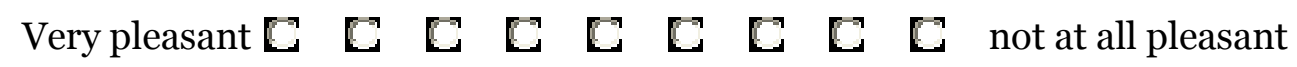

12. Please think of the people that you might possibly forward this message to. Please indicate how many people you would be willing to forward this message to.

Please watch the following message. Please click on the "play" button and wait for the multimedia file to load.

According to the messages you have just viewed, which of the following were risk statements about the HPV vaccine?

13. The vaccine leaves one unprotected against 90 strains of the virus.

$$
\square_{\text {True }} \mathbf{C} \text { False }
$$

14. The vaccine may lead to vaginal discharges.

$$
\mathbf{C} \text { True } \mathbf{C} \text { False }
$$

15. The vaccine may lead to itching. 


$$
\square_{\text {True }} \mathbf{C} \text { False }
$$

16. The vaccine may lead to vaginal sores.

$$
\square_{\text {True }} \boldsymbol{C}_{\text {False }}
$$

17. The vaccine may lead to intolerance to wearing contact lenses.

$$
\square_{\text {True }} \text { False }
$$

18. The vaccine may make one feel pain during intercourse for a short period of time.

$$
\square \text { True } \square \text { False }
$$

19. The vaccine may make one experience numbness of an arm or leg.

$$
\square \text { True } \square \text { False }
$$

20. The vaccine might lead to loss of vision.

$$
\mathbb{a} \text { True } \mathbb{E} \text { False }
$$

21. The vaccine may lead to vaginal bleedings.

$$
[\text { True } \mathbb{E} \text { False }
$$

22. The vaccine might lead to bleeding or spotting between the menstrual periods.

$$
\square \text { True } \square \text { False }
$$


23. The vaccine increases the risk of producing blood clots.

$$
\mathbf{C} \text { True } \mathbf{C} \text { False }
$$

24. The vaccine might lead to decreased appetite.

$$
\square_{\text {True }} \mathbf{C} \text { False }
$$

According to the messages you have just viewed, which of the following were benefit statements about the vaccine?

25. The vaccine will prevent pregnancy.

$$
\mathbf{E} \text { True } \mathbf{C} \text { False }
$$

26. The vaccine may lower the risks of developing breast cancer.

$$
\text { C True } \mathbf{C} \text { False }
$$

27. The vaccine will strengthen the immune system making it able to fight the HPV virus strains that cause most of the genital warts.

$$
\mathbf{C} \text { True } \mathbf{C} \text { False }
$$

28. The vaccine will decrease the chances of developing abnormal cell formations.

$$
\text { C True } \mathbb{C} \text { False }
$$

29. The vaccine will lower the chances of developing pelvic inflammatory diseases. 


$$
\mathbf{C} \text { True } \mathbf{C} \text { False }
$$

30. The vaccine may treat acne.

$$
\square \text { True } \mathbf{C} \text { False }
$$

31. The vaccine will protect one against a common STD.

$$
\mathbf{C}_{\text {True }} \boldsymbol{C}_{\text {False }}
$$

32. The vaccine may decrease the chances of developing genital lesions.

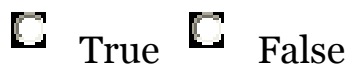

Please answer the following questions about your age, race and education.

33. How old are you?
${ }_{18-23}$
[ 24-29
[30-35

34. What is the highest education level that you have achieved?
C some highschool
highschool
C some college
College
C some graduate studies
G graduate studies 


\section{What race are you?}
C African-American
C Alaskan Native/Native American
C Asian
C Caucasian
C Hispanic
C Other

DISCLAIMER: The messages that you have just seen were created specially for this experiment. They do not reflect the real risks and benefits of being vaccinated with the HPV vaccine. Moreover, there is no vaccine called Hexil. For more information about the HPV virus and the HPV vaccine, please visit the webpage of the Department of Health and Human Services, the Centers for Disease Control and Prevention (CDC): http://www.cdc.gov/std/hpv/ 


\section{Campus IRB Application}

Project Number: 1077497

Review Number: 59387

\section{SECTION A - Investigators}

(1) Research Staff (students must have an advisor listed)

\begin{tabular}{|c|c|c|c|c|}
\hline Name & Dept. & Role & Educational Training Date & \\
\hline & Paul Bolls & Journalism & Advisor & 06-16-2005 \\
\hline & Ana ADI & Journalism & Student Investigator & 12-08-2006 \\
\hline
\end{tabular}

Restriction: All applications must have a primary investigator selected unless they are a student. A student should list themselves as a "student investigator".

Restriction: Student applications must have an advisor listed. Please make sure both you and your advisor are current on the human subjects training (training is good for 2 years) and that your advisor has completed the Advisor Approval Form for this application. The Advisor Approval Form may be accessed under the IRB Forms section of eIRB, and must be submitted by your advisor before submitting this Application to the Campus IRB.

Restriction: All key personnel are required to be IRB certified.

\section{SECTION B - Conflicts of Interest}

\section{(1) Financial Conflicts of Interest}

A. Do you have any financial conflicts of interest in this project? * This includes, but is not limited to, disclosing any proprietary interests, equity interests, significant payments (e.g., grants, compensation in the form of equipment, retainers for ongoing consultation, and honoraria), and whether you receive payment per participant or other incentive payments in this project. Yes__ X_No

B. If yes, please explain those financial conflicts of interest.

\section{(2) Professional Conflicts of Interest}

A. Do you have any professional conflicts of interest in this project? * Yes_X_No

B. If yes, please explain those professional conflicts of interest. 
(3) Institutional Conflicts of Interest

A. Are there any institutional conflicts of interest? *

Yes_X_No

B. If yes, please explain those institutional conflicts of interest.

(4) Personal Conflicts of Interest

A. Do you have any personal conflicts of interest in this project? * Yes_X_No

B. If yes, please explain those personal conflicts of interest.

\section{SECTION C - Project Information}

\section{(1) Project Title *}

Believe it or not - college students' perceptions of the credibility of online audio-video messages

\section{(2) Description *}

Provide a description of the proposed research methodology.

This research will use 2(source) $\mathrm{x} 3$ (emotional tone) online experiment. The source variable is a between subject variable while the emotional tone is a within subjects. Each respondent will see 3 messages attributed to one source, a pharmaceutical company or a governmental agency, and will view three different audio-video messages about the risks and benefits of the HPV vaccine, one being positive, one negative and one coactive (containing both risk and benefit information).

\section{(3) Instruments *}

List each of the instruments used in your study. When listing your instruments (i.e., surveys, questionnaires, inventories, observational techniques, etc.), define the purpose of each instrument and describe the estimated length of time the subject will be engaged in completing the act described in your study. Please add a statement in your consent form explaining each activity and stating the estimated length of time for each activity.

The instrument that will be used for this experiment is the questionnaire. The purpose of the questionaire is to provide the researcher with answers regarding the perceived credibility of the information presented, the subjects' self report of how pleasant/unpleasant the information they were exposed to made them feel, the subjects' recognition of positive, negative, and coactive messages and their behavior of forwarding the information they accessed to their peers. All these questions are meant to bring enswers to the three research questions of this study:

RQ1: How does the source of health audio-video information bites affect the perceived credibility of the information?

RQ2: How does the emotional tone of the information presented in an audio-video bite format affect comprehension?

RQ3: Does the recognition of the risk and benefits influence the respondentis behavior of passing the information along? 
Questionnaire - questions to determine credibility, perception of emotional tone, message recognition, behavior.

\section{(4) Specify the primary location where you intend to collect your data. *}

This research is going employ an online experiment. Therefore, all the information will be uploaded on a free survey website, SurveyArtisan. The data will be collected there and is strictly protected by data encoding and encripting protocols.

\section{(5) Experience *}

Cite the key personnel's experience with this type of research. This includes, but is not limited to, student investigators, advisor, committee members, research staff, co-investigators, etc. Dr. Paul Bolls, my advisor, focuses on cognitive processing of media research. He is the Co-director of the PRIME lab on the MU campus and has more than 10 years of experience in cognitive processing research. Added to his expertise, the members of the thesis committee, Dr.Glen Cameron, Dr. Kevin Wise and Dr. Louise Miller will all bring important input and knowledge from source credibility research, exprimental design and health communication research. The student's investigator experience includes but it is not limited to daily coursework research experience.

(6) Project Dates
A. Start Date *
01-01-2007
B. End Date *
08-31-2007

(7) Is this an international human subjects research project? * Yes__ X_ No

\section{SECTION D - Funding Sources}

Funding Sources

None

SECTION E - Cooperative/Collaborative Activities

Cooperative Sites/Permissions

None 
(1) University of Missouri System Projects

A. Is this project involving other campuses in the University of Missouri system? *

Yes _ X_No

B. If yes, choose the UM campuses involved in the study.

\author{
( ) \\ University of Missouri - Kansas City \\ ( ) \\ University of Missouri - Rolla \\ ( ) \\ University of Missouri - St. Louis
}

(2) Did you obtain IRB or research approval from the research site? * Yes_X_No

(3) Did you upload the approval form or permission letter to this application?

Please UPLOAD the IRB approval form or permission letter from an authorized individual. Yes No

\title{
SECTION G - Risk/Benefits
}

\section{(1) What benefits to society may result from this study? *}

The hope is that by answering the questions of this research the public relations industry, pharmaceutical companies and governmental agencies could find out whether using online multimedia messages technology and uploading them to the company's websites is positively affecting their credibility. It will also help them find a better way to design their messages.

\section{(2) Disclosure of Risks}

\section{A. What level of risk is imposed on the subjects? *} Minimal Risk

B. Describe all risks imposed on subjects in your project. There are no risks imposed on subjects. If they feel threatened or at unease in responding to any of the questions addressed, they can interrupt the experiment at any time.

\section{How do you intend to minimize the risks to the subjects?}

A consent form will be uploaded and presented to the respondents before the beginning of the experiment. If agreeing with the information presented in the consent form, the respondents can proceed to the experiment. They can leave the experiment at any moment by closing the survey window. Their responses up to that point will not be taken into consideration when interpreting the data. 
Moreover, due to the fact that the research relies on fictive information about the risk and benefits of getting the HPV vaccine, the respondents will be offered at the end of the experiment both a link to the official website of the Center for Disease Control and Prevention and downladable material about the HPV virus and the HPV vaccine.

Regarding the behavior question where the respondents will be asked to provide e-mail addresses of those to whom they would forward the information they have just gained, the researcher will use that data only for counting pursposes. No other purpose will be given to that data and it will not be reused or reaccesed after the experiment was completed.

\section{SECTION H - Characteristics}

\section{(1) Number of Subjects *}

Please identify the number of subjects to participate in your project. 100 (one hundred)

\section{(2) Indicate who will be included in your target subject population by checking all that} apply. *

You must complete this section for IRB review.

( )

Children/Youth (7 years of age and under)

( ) Children/Youth (persons between the ages of 8 and 17)

( )

Employees

( ) Mentally Impaired or Legally Incompetent Persons

( ) Minority Persons

( ) Pregnant Females

(X)

Adults (persons 18 and older)

( )

Elderly Persons

( )

Females of Childbearing Age

( )

Incompetent Persons

( )

Low Income Persons

( )

Prisoners 
(X)

Students

\section{(3) Salient Characteristics *}

List the salient characteristics of the targeted subject population in your study.

For the purpose of this study only the responses of female students, be they undergraduate or graduate, with ages between 18 and 26 will be taken into consideration. The reason motivating this sample choice is offered by the HPV vaccine target population.

\section{(4) Exclusions}

What subjects will you specifically exclude from your study?

This research will exclude male subjects and any female respondent that do not fit the age criteria.

\section{(5) Number of Observations *}

List the number of times observations will be made.

1 (one)

\section{(6) Subject Participation *}

How will the subjects participate in the study (i.e., what do the subjects do)?

First of all the subjects will receive an e-mail via the MU listserv inviting them to participate in an experiment. A link to the online experiment will be provided. Once the link is accessed, every respondent will be presented with a consent form explaining how the experiment is going to work and clearly stating that respondents can quit the experiment at any time. Accept/deny buttons will be provided, giving the respondents the choice to opt-in or out of the experiment. Once their consent is obtained, the respondents will be asked about the configuration of the computer they are using, so that they can view the audio-video messages at their best quality. A source will be assigned to each respondent: either the pharmaceutical company or the governmental agency. Respondents will view a short message introducing the first treatment. After viewing the video message the resondents will be asked how pleasant/unpleasant they felt after being exposed to the message. A question about how credible they belive that the source that presented the information they viewed is, will be asked. A scale from 1 to 4 will be provided, where 1 is not at all credible and 4 is very credible. Another question about how pleasant/unpleasant did they feel after being exposed to the message will be given, making sure it's the oposite of the previous question asked. The purpose of this question is to verify the accuracy of the self-reported impact of the message emotional tone. After answering these questions, a distractor will be provided. The same procedure will be repeated with treatements 2 and 3. After viewing all the treatement and all the distractors, respondents will be provided a set of sentences they heard or did not hear in the three treatements. They will be asked to identify in which audio-video message was the information included. After the recognition test is finished, respondents will be asked whether they know anyone facing the risks of the the HPV virus. They can answer with yes, no, I don't know. No matter what they reply, they will be asked whether they would forward to someone the information they have just seen. They can answer with yes, and will be provided with 
space to insert the e-mail addresses or with no. After this procedure, the respondents will be asked a set of demographic questions such as gender, age, level of studies, sexually active or not, and race. Respondents will be thanked for their participation and presented with a message explaining the information they saw was only for the purpose of the experiment. They will be provided with a link to the CDC page and the option of downloading a brochure about the HPV vaccine and the HPV virus. It will also be stated that the e-mail addresses they provided will be used only for counting purposes, and their peers will not be contacted. A thank you message will be displayed and the option of closing the window and exiting the experiment will follow.

\section{SECTION I - Participation}

\section{(1) Subject Recruitment *}

Please describe how the subjects will be recruited. Remember to upload any supportive documentation (fliers, letters, verbal scripts, etc.) that you intend to use when recruiting potential subjects.

A short e-mail presenting the research and the fact that it represents the topic of a master's thesis is going to be sent to several list servs belonging to the University of Missouri.

\section{(2) Subject Selection}

Please describe how subjects are selected.

\section{(3) Subject Participation}

\section{A. Is subject participation anonymous, confidential, or other? *}

The subjects participation is anonymous.

\section{B. Please explain. *}

There are no personal data that will be asked from the respondents. The information regarding their peers' e-mail addresses is confidential and the e-mails will be used only to be counted. They will not be stored in a separate database and will not be used for any other research.

\section{(4) Subject Inducement}

\section{A. Are you offering an inducement for the subjects' participation? * Yes_X_No}

\section{B. If yes, describe the offered inducement.}

If you intend to compensate research participants with payments, cash, or non-cash items such as credits to student accounts or other items of value, please contact Accounting Services at 882-3051 or newellgroshong@missouri.edu to implement a system consistent with accounting protocol prior to the distribution of such compensation. If you have any questions, please click on the above help link.

C. Have you contacted the Accounting Services Department at 882-3051 or newellgroshong@missouri.edu to assure the proposed payment distribution complies with the policies of the University of Missouri? 
Yes No

D. If you are offering extra credit incentives for student participation, describe the alternative inducement for students who may decline.

Federal regulations require the Board to ensure there are no coercive elements in human research projects. Pursuant to 45 CFR 46.111(b), "When some or all of the subjects are likely to be vulnerable to coercion or undue influence... additional safeguards have been included in the study to protect the rights and welfare of these subjects."

\section{(5) Access to Student Grades *}

\section{A. Are you requesting information about student's grades? ${ }^{*}$} Yes $\quad \mathrm{X} \_$No

B. Have you contacted the authorized registrar? Yes_X_No

\section{SECTION J - Consent Process}

\section{(1) Informed Consent}

\section{A. What type of consent will be used? * Written}

\section{B. Describe the informed consent process in detail. *}

You are invited to participate in a research study in which you will view a few multimedia messages. You will then be asked a few questions related to the messages you have just seen. Your participation in this experiment should not take longer than 15 minutes.

If you have any questions regarding this study, please contact:

Ana ADI by phone 5736390575 or by e-mail at aay59@mizzou.edu

If you have read this form and decide to participate in this project, please understand your participation is voluntary, and you have the right to withdraw your consent or discontinue participation at any time without penalty. You have the right to refuse to answer any question. In addition, your individual privacy will be maintained in all published and written work resulting from this study. Your participation will help researchers learn more about how people process multimedia information. There are no other benefits.

If you have questions about your right as a study participant, or are dissatisfied at any time with any aspect of this study, you may contact, anonymously if you wish, the Campus Institutional Review Board, 483 McReynolds, University of Missouri, Columbia, MO 65211 or by phone at (573) 882-9585.

I agree (button $\dot{c}$ start experiment)

I disagree (button $\dot{c}$ exit experiment)

\section{(2) Waiver of Consent}

A. If you are requesting a waiver of consent, please explain the rationale for your 
request in detail.

B. Will a waiver of consent harm the subjects in any way? Yes No

C. If no, explain how a waiver of consent would not harm the subjects.

D. If you are requesting a waiver of consent, are there any alternatives to the waiver? Yes No

E. If yes, describe the alternatives to waiving consent.

F. If you are requesting a waiver of consent, do you intend to include a debriefing opportunity for the subjects?

Yes No

G. If yes, describe the debriefing process.

(3) Language Barriers

A. Are there any language barriers between you and the subjects in your project? Yes___ _ No

B. If yes, how do you propose to manage the language barrier?

SECTION K - Data Collection

\section{(1) Data Anonymity/Confidentiality of Data}

A. Will the data collected be anonymous, confidential or neither? *

Data is anonymous if it is recorded in such a manner that human subjects cannot be directly identified, or through identifiers linked to the subjects. Data collected in a manner where it contains identifiers which can be linked to subjects is not anonymous, but can be kept confidential through means including, but not limited to, aggregate reporting, assigning codes, removal of identifiers, etc.

$\mathrm{X} \_$Anonymous Data
Confidential Data
Neither Anonymous Nor Confidential

B. How do you intend to protect the confidentiality of the data collected? *

The e-mail addresses required from the participants will not be collected in a separate database and will not be used for other purposes than mere counting of the number of rferrals made. The data gathered in this way will be destroyed after is analyzed.

C. Do you intend to obtain a Certificate of Confidentiality? * If yes, submit a copy of the Certificate of Confidentiality.

Yes_X_No

(2) Data Sharing *

A. Do you intend to publish or share data from this project? 


$$
\text { Yes_X_No }
$$

B. If yes, identify the person/entity with whom you intend to share or publish the data.

\section{(3) Result Sharing}

A. Do you intend to publish or share the results from this project? *

$$
\mathrm{X} \_ \text {Y Yes _ No }
$$

B. Please explain. *

If data obtained is conclusive, I intend to present the research results at a conference or to submit an article for a specialized journal

\section{(4) Data \& Records}

A. Are you a member of any one of the following entities: MU Health Care, Student Health Center, Intercollegiate Athletics, the Consultation and Assessment Clinic, the Psychology Clinic, or the Counseling Center? Yes__ X_No

B. Are you sharing data with any one of the following entities: MU Health Care, Student Health Center, Intercollegiate Athletics, the Consultation and Assessment Clinic, the Psychology Clinic, or the Counseling Center? Yes__ X_No

C. Do you possess, or will you be obtaining health records of the subjects? Yes_X_No

\section{SECTION L - Blood Information}

(1) Do you intend to collect blood samples in this project? * Yes_X_No

(2) If blood will be drawn, enter the following information

A. Explain the purpose for drawing blood sample(s).

B. Type of blood

C. Identify the location from where the blood is drawn.

D. How many times will blood be drawn from the subject?

E. Identify the amount of blood drawn each instance.

F. List the qualifications of the individual drawing the blood sample.

G. Identify the location where the blood will be stored.

H. Identify the individuals who have access to the blood sample.

I. Who is paying for having the blood drawn?

J. Identify persons/entities with which you intend to share data from the blood sample. 


\section{SECTION M - Drugs}

Drugs used in the study

None

\section{SECTION N - Drug Side Effects}

(7) Drug Side Effects

SECTION O - HIPAA Regulations

(1) HIPAA Regulations

HIPAA Category: No HIPAA requirement

$\&^{*}=$ Required Question 
Project

Number:

1077497

Project Title: Believe it or not - college students ` perceptions of the credibility of online audio-video messages

Approval Date: 02-09-2007

Expiration

Date:

02-09-2008

Investigator(s): $\mathrm{ADI}$, Ana

Bolls, Paul David

Level Granted: Expedited

\section{CAMPUS INSTITUTIONAL REVIEW BOARD APPROVAL FORM UNIVERSITY OF MISSOURI-COLUMBIA}

This is to certify that your research proposal involving human subject participants has been reviewed by the Campus IRB. This approval is based upon the assurance that you will protect the rights and welfare of the research participants, employ approved methods of securing informed consent from these individuals, and not involve undue risk to the human subjects in light of potential benefits that can be derived from participation.

Approval of this research is contingent upon your agreement to:

(1) Adhere to all UMC Policies and Procedures Relating to Human Subjects, as written in accordance with the Code of Federal Regulations (45 CFR 46).

(2) Maintain copies of all pertinent information related to the study, included but not limited to, video and audio tapes, instruments, copies of written 
informed consent agreements, and any other supportive documents for a period of three (3) years from the date of completion of your research.

(3) Report potentially serious events to the Campus IRB (573-882-9585) by the most expeditious means and complete the eIRB "Campus Adverse Event Report". This may be accessed through the following website: http://irb.missouri.edu/eirb/.

(4) IRB approval is contingent upon the investigator implementing the research activities as proposed. Campus IRB policies require an investigator to report any deviations from an approved project directly to the Campus IRB by the most expeditious means. All human subject research deviations must have prior IRB approval, except to protect the welfare and safety of human subject participants. If an investigator must deviate from the previously approved research activities, the principal investigator or team members must:

a. Immediately contact the Campus IRB at 882-9585.

b. Assure that the research project has provisions in place for the adequate protection of the rights and welfare of human subjects, and are in compliance with federal laws, University of Missouri-Columbia's FWA, and Campus IRB policies/procedures.

c. Complete the "Campus IRB Deviation Report". This may be accessed through the following website: http://irb.missouri.edu/eirb/.

(5) Submit an Amendment form to the Campus IRB for any proposed changes from the previously approved project. Changes may not be initiated without prior IRB review and approval except where necessary to eliminate apparent and immediate dangers to the subjects. The investigator must complete the Amendment form for any changes at http://irb.missouri.edu/eirb/.

(6) Federal regulations and Campus IRB policies require continuing review of research projects involving human subjects. Campus IRB approval will expire one (1) year from the date of approval unless otherwise indicated. Before the one (1) year expiration date, you must submit Campus IRB Continuing Review Report to the Campus IRB. Any unexpected events are to be reported at that time. The Campus IRB reserves the right to inspect your records to ensure compliance with federal regulations at any point during your project period and three (3) years from the date of completion of your research. 


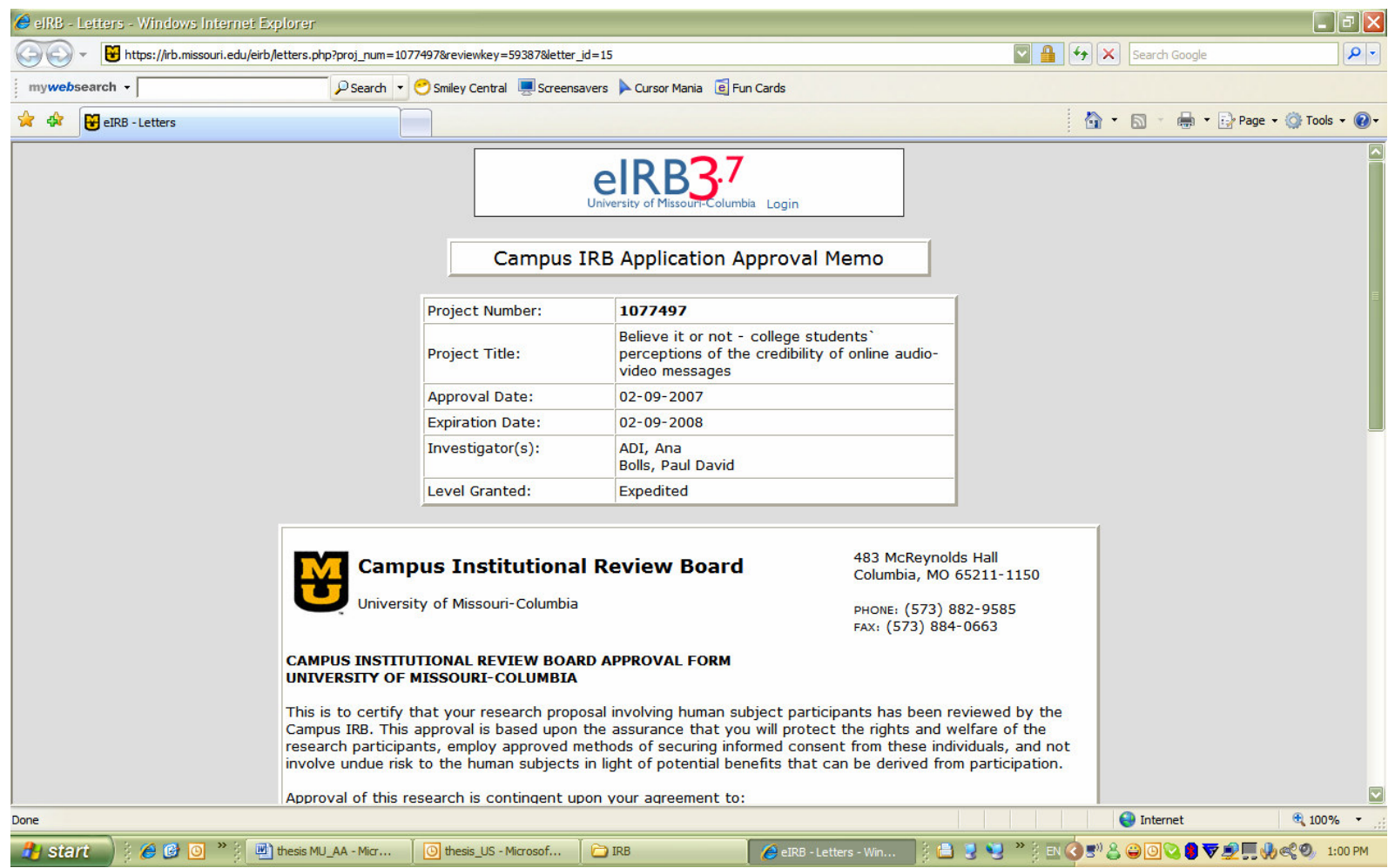




\begin{tabular}{|c|c|c|c|c|}
\hline \multicolumn{5}{|c|}{$\begin{array}{c}\text { Campus IRB Continuing Review Report } \\
\text { Project Number: } 1077497 \\
\text { Review Number: } 63118\end{array}$} \\
\hline \multicolumn{5}{|c|}{ SECTION A - Project Information } \\
\hline \multicolumn{5}{|c|}{ (1) Project Title } \\
\hline \multicolumn{5}{|c|}{ Believe it or not - college students` perceptions of the credibility of online audio-video messages } \\
\hline \multicolumn{5}{|c|}{ (2) Level of Review } \\
\hline \multicolumn{5}{|c|}{ Expedited } \\
\hline \multicolumn{5}{|c|}{ (3) On-Site Principal Investigator } \\
\hline \multicolumn{5}{|c|}{ Principal Investigator: } \\
\hline \multicolumn{5}{|c|}{ Department/Division: } \\
\hline \multicolumn{5}{|c|}{ Telephone \#: } \\
\hline \multicolumn{5}{|c|}{ Address: } \\
\hline \multicolumn{5}{|c|}{ E-Mail: } \\
\hline \multicolumn{5}{|c|}{ (4) Key Personnel } \\
\hline \multirow[t]{3}{*}{ Name } & Dept. & Role & Educational Tr & \\
\hline & Bolls, Paul David & Journalism & Advisor & 06-16-2005 \\
\hline & ADI, Ana & Journalism & Student Investigator & 12-08-2006 \\
\hline \multicolumn{5}{|c|}{ SECTION B - Conflicts of Interest } \\
\hline \multicolumn{5}{|c|}{ (1) Financial Conflicts of Interest } \\
\hline \multicolumn{5}{|c|}{$\begin{array}{l}\text { A. Do you have any financial conflicts of interest in this project? } * \\
\text { Yes _ }{ }^{*}{ }_{-} \text {No }\end{array}$} \\
\hline
\end{tabular}


(2) Professional Conflicts of Interest

A. Do you have any professional conflicts of interest in this project? ${ }^{*}$ Yes____ No

B. If yes, please explain those professional conflicts of interest.

(3) Institutional Conflicts of Interest

A. Are there any institutional conflicts of interest? ${ }^{*}$ Yes____ No

B. If yes, please explain those institutional conflicts of interest.

(4) Personal Conflicts of Interest

A. Do you have any personal conflicts of interest in this project? $*$ Yes__ X_ No

B. If yes, please explain those personal conflicts of interest.

\section{SECTION C - Consent Process}

(1) Type of Consent (Oral or Written) *

A. Are you using oral consent? *

$$
\text { Yes_X_No }
$$

B. Are you using written consent? *
_- X_Y Yes No

(2) Did you originally request a waiver of consent/assent? ${ }^{*}$

$$
\text { Yes_X_No }
$$

\section{SECTION D - Project Status}

\section{(1) Data *}

\section{A. Are you actively collecting data? $*$}

If you are actively collecting data, please upload a copy of your current consent form. Your project will not be reviewed until we have received the consent form.

$$
\text { Yes_X_No }
$$

B. Are you currently analyzing the data? ${ }^{*}$ Yes_X_No 
C. Do you intend to collect further data? $*$

If you intend to collect further data, please attach a copy of the consent form. Yes_X_No

\section{(2) Project Withdrawal *}

\section{A. Do you request to withdraw the project? $*$} Yes_X_No

B. If yes, please state the reason for project withdrawal:

\section{(3) Project Completion *}

A. Have you completed the collection and analysis of the data for this project? * _. X_Y Yes No

B. If yes, please provide the date of completion: 04-25-2007

\section{SECTION E - Current Funding Source}

\section{(1) Current Funding Source(s)}

\section{SECTION F - Project Summary}

\section{(1) Provide a brief description of the project. *}

Attach a detailed summary of any findings, literature, or relevant information that relates or is in support of the project. Additionally, please explain your methodology.

The first research question focused on how the emotional tone of an online multimedia message influences the perceived credibility of its releasing source. The emotional tone affects significantly both the perceived authoritativeness $(\mathrm{F}(2,308)=41.225, \mathrm{p}<.000$, eta squared $=.211)$ and the perceived character $(\mathrm{F}(2,308)=$ $6.911, \mathrm{p}<.000$, eta squared $=.043$ ). This indicates that there is a main effect of emotional tone on the perceived credibility of a source. Additionally, results indicate that people perceive sources releasing coactive messages as the least authoritative, while those releasing negative messages as having less character. Furthermore, post-hoc analysis revealed that there are significant differences in the perception of positive and coactive messages as well as that of negative and coactive messages. However, no significant difference was found between positive and negative messages.

Statistical analysis also showed that the emotional tone of a message had a more powerful effect on the perceived authoritativeness of a source (eta squared $=.211$ ) that on its perceived character (eta squared $=.043$ ). Moreover, data demonstrated that the source, be it a pharmaceutical company or a governmental health agency, did not influence the perceived credibility.

The second research question investigated how the emotional tone of a message influences the respondents $i$ behavior of forwarding the message to their peers. Data showed that the emotional tone was influential on people $i s$ willingness to forward the message. Coactive $($ mean $=5.54)$ and positive $($ mean $=5.22)$ messages are more likely to be forwarded than the negative (mean $=3.74)$ ones. Due to the skewness of the data computing 
an average for the number of people to whom the messages would be forwarded in each of the three categories is not sensible.

(2) Data Anonymity/Confidentiality of Data *

A. Is the data collected confidential, anonymous, or neither? $*$

Data was confidential.

B. How do you intend to protect the confidentiality of the data? ${ }^{*}$

Respondents were not asked for their names or e-mail addresses. Their participation was voluntary and their responses cannot be tracked back to them. In addition, the results will be archived for the following 3 years and data will not be disclosed to any third parties.

C. Did you obtain a Certificate of Confidentiality? $*$ Yes_X_No

(3) Adverse Events *

A. Did any Adverse Events or unanticipated problems occur? * Yes_X_No

B. If yes, provide an explanation and contact the Campus IRB office immediately.

(4) Subjects *

A. Total number of subjects enrolled: * 223

B. Total number of subjects who complained: *

Attach a copy of all written complaints and a summary of all verbal complaints.

No complaints

C. Total number of subjects who withdrew: *

76

D. Please provide an explanation for the subject's withdrawal.

Due to the fact that the experiment was online, subjects might have abandoned the experiment when they realized that they were running out of time. Also, some of them could have opted out of the experiment when they realized that their computer has either a very slow internet connection or is not equiped with speakers, a device that absolutely necessary for the good development of the research.

\section{(5) Data Publishing *}

A. Do you intend to publish or share the collected data? $*$ Yes __ _ _ No 
B. Provide a list of whom you intend to share the data with:

\section{SECTION G - Modifications}

(1) Changes or Modifications *

A. Were there any changes or modifications to this project? $*$ Yes_X_No

B. Identify any changes or modifications that have been made to this project.

(2) IRB Approval

A. Have these changes or modifications received IRB approval? Yes No

B. If no, please explain and contact the IRB office immediately:

C. If yes, please provide the date of approval.

(3) Identify any changes or modifications that could impact the board's understanding of the risks and benefits of the research project OR that may affect the board's approval decision.

(4) Identify any changes or modifications that could impact the subject's informed consent.

\section{SECTION H - HIPAA Regulations}

(1) HIPAA Regulations

HIPAA Category: No HIPAA requirement

$$
\& *=\text { Required Question }
$$




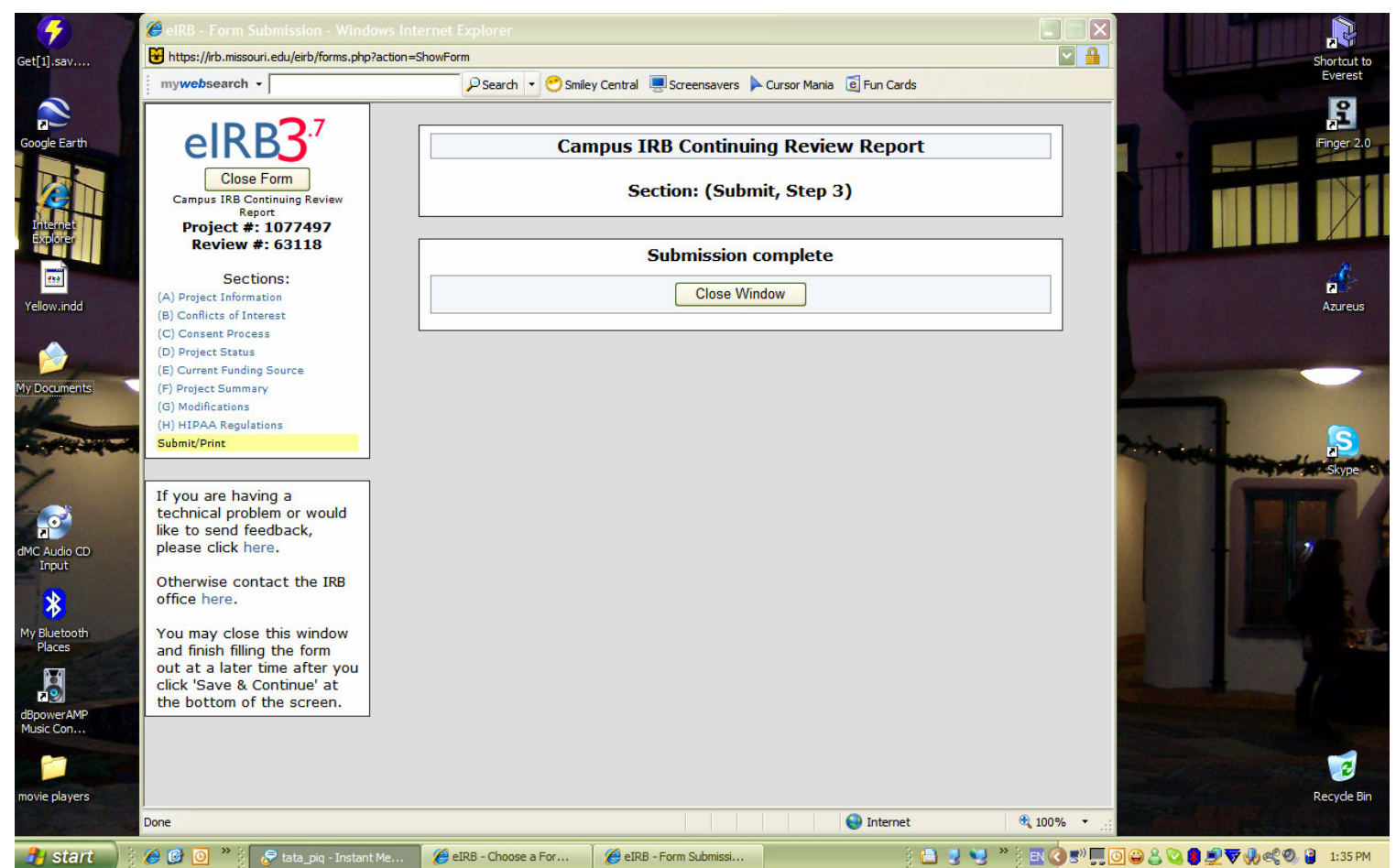




\section{\& BIBLIOGRAPHY d}

Ackard, D. M., \& Neumark-Sztainer, Dianne. (2001). Health Care Information Sources for Adolescents: Age and Gender Differences on Use, Concerns, and Needs. Journal of Adolescent Health, 29, 170-176.

Ball, L. K., Evans, G., \& Bostrom, A. (1998). Risky business: challenges in vaccine risk communication. Pediatrics, 101(3), 453-458.

Berger, C. R. C., S. H. . (1989). Handbook of Communication Science. Newbury Park, CA: Sage.

Biro, F. M., Rosenthal, S.L., Kollar, L.M, \& Hillard, P.J.A. (1997). Adolescent girls' understanding of Papanicolau smear results. Journal of Pediatric and Adolescent Gynecology, 10(209-212).

Bolls, P. D., Lang, A. \& Potter, R. E. . (2001). The Effects of Message Valence and Listener Arousal on Attention, Memory, and Facial Muscular Responses to Radio Advertisements. Communication Research, 28(5), 627-651.

Borzekowski, D. L. G., \& Rickert, V.I. (2001). Adolescent cybersurfing for health information a new resource that crosses barriers. Archives of Pediatric and Adolescent Medicine, 155, 813-817.

CDC. (2001). Sexually Transmitted Diseases in the US: New Numbers from the CDC. Retrieved March, 2007, from

http://healthlink.mcw.edu/article/976735469.html

Eysenbach, G., Christian Köhler. (2002). How do consumers search for and appraise health information on the world wide web? Qualitative study using focus groups, usability tests, and in-depth interviews. British Medical Journal 324, 573-577.

Dempsey, A. F., Zimet, G. D., Davis, R. L., \& Koutsky, L. (2006). Factors that are associated with parental acceptance of Human Papillomavirus vaccines: A randomized intervention study of written information about HPV. Pediatrics, 117(5), 1486-1493.

Fogg, B. (2003). Persuasive Technology. San Francisco: Morgan Kaufmann. 
Fogg, B., Tseng, H. (1999). The elements of computer credibility. In Proceeding of the CHI 99 Conference on Human Factors in Computing Systems (pp. 80-89).

Fox, S., \& Lee, R. (2002). Vital decisions: how internet users decide what information to trust when they or their loved ones are sick. Plus a guide from the Medical Library Association about smart health-search strategies and god websites.

Fox, S., Rainie, Lee et al. (2001). The online health care revolution: How the Web helps Americans take better care of themselves. Retrieved July, 2006, from http://www.healthprivacy.org/

Gaziano, C., McGarth, K. (1986). Measuring the concept of credibility. Journalism Quarterly, 65, 451-462.

Goold, P. C., Ward, M., \& Carlin, E.M. (2003). Can the internet be used to improve sexual health awareness in web-wise young people? Journal of Family Planning and Reproductive Health Care, 29(1), 28-30.

Grabe, M. E., \& Westley, B.H. (2003). The Controlled Experiment. In Stempel, G.H. III, Weaver, D. H. \& Wilhoit, C. G. (Ed.), Mass communication research and theory (pp. 267-298). Boston : Allyn and Bacon

Gray, N. J., Kleinb, Jonathan D., Noycec, Peter R., Sesselbergb, Tracy S., \& Cantrillc, Judith A. (2005). Health information-seeking behaviour in adolescence: the place of the internet Social Science \& Medicine 6o(7), $1467-1478$

Gynecologic Problems: Human Papillomavirus Infection. (1999). Washington, D.C: American College of Obstetricians and Gynecologists Patient Education Pamphlet.

Hanauer, D., Dibble, E., Fortin , J. \& Col, N.F. (2004). Internet use among community college students implications in designing healthcare interventions. Journal of American College Health, 52(5), 197-202.

Hansen, D. L., Derry, H.A., Resnick, P.J. \& Richardson, C.R. (2003). Adolescents searching for health information on the internet: an observational study. Journal of Medical Internet Research, 5(4), e25.

Homer, M. (2004). College males' awareness of and attitudes toward the Human Papillomavirus (pp. 1-123): University of Florida.

Hoover, D. R., Carfioli, Beth, \& Moench, Elisabeth A. (2000). Attitudes of 
Adolescent/Young Adult Women Toward Human Papillomavirus Vaccination and Clinical Trials. Health Care for Women International, $21,375-391$.

Horn, J. E., McQuillan, G.M., Ray, P.A., \& Hook, E.W. (1990). Reproductive health practices in women attending an inner city STD clinic. Sexually Transmitted Diseases, 17, 133-137.

Hovland, C. I., \& Weiss, W. (1951). The influence of source credibility on communication effectiveness. Public Opinion Quarterly, 15(635-650).

Jennings, K. M. (1997). Getting a Pap smear: Focus group responses of African American and Latino women. Oncology Nursing Forum, 24, 827-835.

Juberlier, S. J., Blanton, P.D., Zhang, J., Foster, D., Monk, J., Kuhn, G., \& Hanshew, D. (1996). Assessment of knowledge, attitudes and behaviors relative to cervical cancer and Pap smears among adolescent girls in West Virginia. Journal of Cancer Education, 11, 230-232.

Kahn, J. A., Rosenthal, S.L., Hamman, T, \& Bernstein, D.I. (2003). Attitudes about Human Papillomavirus vaccine in young women. International Journal of Sexually Transmitted Diseases 14, 300-306.

Kanuga, M., \& Rosenfeld, Walter D. . (2004). Adolescent sexuality and the internet the good, the bad, and the URL. Journal of Pediatric and Adolescent Gynecology, $17(2), 117-124$.

Kimmel, S. R., \& Wolfe, R.M. (2005). Communicating the benefits and risks of vaccines. The Journal of Family Practice, 54(1), S51-S57.

Lachman, R., Lachaman, J.L., \& Butterfield, E.C. (1979). Cognitive psychology and information processing: An introduction. Hillsdale, NJ: Erlbaum.

Lang, A. (2000). The limited capacity model of mediated message processing. Journal of Communication, 5O(1), 46-71.

Lang, A. (2006). Using the Limited Capacity Model of Motivated Mediated Message Processing to Design Effective Cancer Communication Messages. Journal of Communication, 56, S57-S80.

Lang, A., Bolls, P., \& Kawahara, K. . (1996, April ). The Effects of Arousing Message Content and Structural Complexity on Television Viewers' Arousal and Allocation of Processing Resources. Paper presented at the Midwest Artificial Intelligence and Cognitive Science Conference. 
Lang, A., Dhillon, P., \& Dong, Q. (1995). Arousal, emotion and memory for television messages. Communication Research, 20, 647-670.

Lasswell, H. D. (1948). The structure and function of communication society. In L. Bryson (Ed.), The communication of ideas (pp. 37-51). New York: Harper.

Markowitz, L.E., Dunne, E. F., Saraiya, M., Lawson, H.W., Chesson, H., \& Unger, E.R. (2007) Quadrivalent Human Papillomavirus Vaccine . Morbidity and Mortality Weekly Report, 56(RR02);1-24

Mayeaux, E. J. (2005). Overcoming barriers to HPV vaccine acceptance. The Journal of Family Practice(Special Edition), S17-S22.

Merck. (2007). Gardasil. Retrieved March, 2007, from http://www.gardasil.com/

Morahan-Martin, J. M. (2004). How Internet Users Find, Evaluate, and Use Online Health Information: A Cross-Cultural Review. CyberPsychology \& Behavior, 7(5), 497-510.

Moscovici, S. (1984). The phenomenon of social representations. In R. M. F. S. Moscovici (Ed.), Social representatives (pp. 3-69). New York: Cambridge University Press.

Nass, C, \& Sundar, S.S. (2001). Conceptualizing Sources in Online News. Journal of Communication, 51(1), 52-72.

Neumark-Sztainer, D. M. A. D. (2001). Health Care Information Sources for Adolescents: Age and Gender Differences on Use, Concerns, and Needs. Journal of Adolescent Health, 29, 170-176.

Pornitakpan, C. (2004). The Persuasiveness of Source Credibility: A Critical Review of Five Decades' Evidence. Journal of Applied Social Psychology, 34 ( 2), 243-281.

Ramirez, J. E., Ramos, D.M., Clayton, L., Kanowitz, S., \& Moscicki, B. (1997). Genital Human Papillomavirus infections: Knowledge, perception of risk, and actual risk in a non-clinic population of young women. Journal of Women's Health, 6, 113-121.

Reeves, B., \& Geiger, Seth. (1994). Designing Experiments That Assess Psychological Responses to Media Messages. In A. Lang (Ed.), 
Measuring Psychological Responses to Media (pp. 165-180). Hillsdale, New Jersey: Lawrence Erlbaum Associates.

Richardson, K. P. (2003). Health risks on the internet: establishing credibility online. Health, Risk \& Society, 5(2), 171-184.

Rideout, V. (2001). Generation Rx. com how young people use the internet for health information. Menlo Park, CA: Kaiser Family Foundation.

Rubin, R. M. (1994). Source Credibility Scale - McCroskey. In P. P. H. E. S. Rebecca B. Rubin (Ed.), Communication Research Measures. A sourcebook (pp. 332-339). New York: The Guilford Press.

Sandwick, H. (1999). Health Information and interaction on the Internet. British Medical Journal, 319, 29-32.

Shannon, C., \& Weaver, W. (1949). The mathematical theory of communication Urbana: University of Illinois Press.

Shon, J., Marshall,J., \& Musen, M. . (2000). The impact of displayed awards on the credibility and retention of Web site information. Paper presented at the AMIA Sympozion.

Schramm, W. (1954). How communication works. In W. Schramm (Ed.), The process and effects of mass communication (pp. 3-26). Urbana: University of Illinois Press.

Simons, H., Berkowitz, N., \& Moyer, R. . (1970). Similarity, credibility, and attitude change: a review and a theory. Psychological Bulletin, 73, 1-16.

Slater, M. D., \& Rouner, D. . (1996). How message evaluation and source attributes may influence credibility assessment and belief change. Journalism \& Mass Communication Quarterly, 73, 974-991.

Thornburg, H. D. (1981). Adolescent sources of information on sex. Journal of School Health, 5(4), 274-277.

van den Berg, B. J., . \& Parry, M. A. (1983). Adolescents' preference of source to obtain contraceptive information. American Journal of Obstetrics and Gynecology, $147(6), 719-721$.

Weaver, S. T. K. D. (2002). Communication research about the internet: a thematic meta-analysis. New Media \& Society, 4(4), 518-538. 